Review Article

\title{
Epigenetic Control of Macrophage Polarisation and Soluble Mediator Gene Expression during Inflammation
}

\author{
Theodore S. Kapellos and Asif J. Iqbal \\ Sir William Dunn school of Pathology, South Parks Road, Oxford OX1 3RE, UK \\ Correspondence should be addressed to Asif J. Iqbal; asif.iqbal@path.ox.ac.uk \\ Received 18 February 2016; Accepted 28 March 2016 \\ Academic Editor: Eduardo López-Collazo
}

Copyright ( 2016 T. S. Kapellos and A. J. Iqbal. This is an open access article distributed under the Creative Commons Attribution License, which permits unrestricted use, distribution, and reproduction in any medium, provided the original work is properly cited.

\begin{abstract}
Macrophages function as sentinel cells, which constantly monitor the host environment for infection or injury. Macrophages have been shown to exhibit a spectrum of activated phenotypes, which can often be categorised under the M1/M2 paradigm. M1 macrophages secrete proinflammatory cytokines and chemokines, such as TNF- $\alpha$, IL-6, IL-12, CCL4, and CXCL10, and induce phagocytosis and oxidative dependent killing mechanisms. In contrast, M2 macrophages support wound healing and resolution of inflammation. In the past decade, interest has grown in understanding the mechanisms involved in regulating macrophage activation. In particular, epigenetic control of $\mathrm{M} 1$ or $\mathrm{M} 2$ activation states has been shown to rely on posttranslational modifications of histone proteins adjacent to inflammatory-related genes. Changes in methylation and acetylation of histones by methyltransferases, demethylases, acetyltransferases, and deacetylases can all impact how macrophage phenotypes are generated. In this review, we summarise the latest advances in the field of epigenetic regulation of macrophage polarisation to M1 or M2 states, with particular focus on the cytokine and chemokine profiles associated with these phenotypes.
\end{abstract}

\section{Macrophages Are a Heterogeneous Population Tightly Controlled by Tissue-Specific Factors}

Macrophages are immune cells of myeloid lineage that originate from the embryonic yolk sac and are an integral component of the host's immune response. They act as sentinel cells, which constantly sample their microenvironment and their primary function is to monitor tissues for potential threats (e.g., infection and injury). There are a range of resident macrophage populations, including microglia (brain), Kupffer cells (liver), alveolar macrophages (lungs), splenic macrophages, osteoclasts, bone marrow macrophages, histiocytes (connective tissue), intraocular macrophages (eye), subcapsular sinusoidal macrophages (lymph nodes), and intestinal macrophages $[1,2]$.

All macrophage populations monitor their tissue of residence and respond to pathogen-associated molecular patterns (PAMPs) and danger-associated molecular patterns (DAMPs) by initiating the acute inflammatory cascade. After clearance of the pathogenic factors, resident macrophages replenish their populations by proliferation and promote the resolution of inflammation by clearing apoptotic cells/debris and support wound healing and tissue repair programs $[1,3]$.

In addition to these generic roles, macrophages demonstrate tissue-specific functional properties [3]. For example, resident populations in mucosal areas come into contact with environmental pathogens and splenic macrophages control iron metabolism together with Kupffer cells and clear senescent erythrocytes from the circulation. In the brain, microglia cells play a crucial role in neuronal survival [3].

To carry out their tissue-specific functions, macrophages respond to local signals released in their niche. For instance, it has been shown that retinoic acid in the peritoneal cavity and TGF- $\beta$, CSF-1, and IL-34 in the brain help define peritoneal macrophages and microglia populations, respectively $[2,4]$. CSF-1 and RANKL induce differentiation of osteoclasts, CSF-2 secretion by the respiratory epithelium matures alveolar macrophages, and IL-10 prevents excessive intestinal macrophages activation $[2,4]$. Under this constant 
conditioning, the macrophage lineage is established via expression of signature transcription factors (TFs), which dictate their functions not only in homeostasis, but also during an immune response.

Examples include the ability of peritoneal macrophages to signal via eicosanoid products, microglia to undergo oxidative metabolism, alveolar macrophages to metabolise lipids, and red pulp splenic macrophages to respond to interferon activation [5]. Recently, many reports have identified core genes that define macrophage populations in the host. Tissue-specific TF regulate tissue signature genes by binding to motifs on enhancers to control gene expression. For example, Spic has been shown to be the signature TF for red pulp splenic macrophage development, Gata6 is responsible for $T g f b 2$, Cebpb, and Rarb expression in peritoneal macrophages, Runx3 in intestinal macrophages, Car4 in alveolar macrophages, Clec4f in Kupffer cells, and $M e f 2 c$ in microglia [2, 4-7]. In some cases, subpopulations of resident macrophages may express their own selective signature genes; for instance, small peritoneal macrophages express Ciita, which is detected at low levels in large peritoneal macrophages [4].

These transcriptional differences result in selective expression of proteins by different macrophage populations, for instance, VCAM-1 and CD31 in splenic macrophages, CX3CR1 and Siglec-H in microglia, ICAM-2 and CD93 in peritoneal macrophages, CCR2 in monocytes, CLEC4F in Kupffer cells, or CD1la and EpCAM in alveolar macrophages $[2,5,6]$. These proteins are critical in recruiting and integrating macrophage populations into their respective niches.

\section{Macrophage Differentiation and Immune Responses Are Regulated by Complex Epigenetic Changes}

Macrophages are constantly sampling their ever changing environment and have therefore evolved regulatory epigenetic programs that define their core functions and also allow them to respond to environmental cues rapidly.

The lineage determination of macrophages is accomplished by the constitutive expression of the ETS-domain TF and PU.1. PU.1 can bind to its motifs on DNA and facilitate stable opening of chromatin and recruitment of additional TF (Figures 1(a) and 1(b)). It is found at macrophage gene enhancers and promoters and contributes to enhancer organisation [8-10]. In vitro ectopic expression of PU.1 in fibroblast cell lines has been shown to induce the expression of macrophage-specific genes, such as Cd68, Emrl, and $L y z 2$, illustrating its significance for the establishment of the macrophage lineage [11].

However, recent evidence has shown that PU.1 does not establish the macrophage lineage on its own (Figure 1(b)). In fact, PU.1 binding motifs on promoters are in close proximity to other macrophage TF, such as AP-1, C/EBP $\alpha, \mathrm{C} / \mathrm{EBP} \beta$, and RUNX. Evidence from Heinz et al. suggests that cross-talk between PU.1 and C/EBP $\beta$ supports the organisation of the macrophage enhancer landscape [8].
The basic unit of DNA organisation in cells, the nucleosome, consists of 147 base pairs of DNA wrapped around a dimer of tetramers of the core histone proteins, H2A, H2B, $\mathrm{H} 3$, and $\mathrm{H} 4$. The nucleosomes pack the DNA efficiently in the nucleus, but at the same time they obstruct DNA from being transcribed. In order for transcription to occur, the core histones undergo modifications and unravel in a process called nucleosome remodelling. Key histone modifications that regulate gene expression include $\mathrm{H} 3$ and $\mathrm{H} 4$ methylation and acetylation [12].

During macrophage differentiation, lineage-specific enhancers and promoters are marked epigenetically with histone modifications [10]. Enzymes transfer methyl groups to histone tails resulting in positive or negative regulation of adjacent gene expression. The chemical reaction is targeted to lysine $(\mathrm{K})$ or arginine $(\mathrm{R})$ residues on $\mathrm{H} 3$ and $\mathrm{H} 4$ and the enzymes show high selectivity for their targets $[13,14]$. Gene promoters are labelled with $\mathrm{H} 3 \mathrm{~K} 4 \mathrm{me} 3$, whilst enhancers are marked with $\mathrm{H} 3 \mathrm{~K} 4 \mathrm{mel}$ (Figure 1(b)). Promoters are invariably labelled with $\mathrm{H} 3 \mathrm{~K} 4 \mathrm{me} 3$, regardless of whether the genes are expressed or not. They may acquire additional $\mathrm{H} 3 \mathrm{~K}$ /14ac marks as a signature of transcription initiation and $\mathrm{H} 3 \mathrm{~K} 36 \mathrm{me} 3$ and $\mathrm{H} 3 \mathrm{~K} 79 \mathrm{me} 2$ as signatures of transcription elongation [15].

Regulation of gene expression in macrophages has been reported to occur mainly at the level of enhancers. Active enhancers present deposition of $\mathrm{H} 3 \mathrm{~K} 27 \mathrm{ac}$ [16] and therefore feature as H3K4me1 ${ }^{\mathrm{hi}} \mathrm{H} 3 \mathrm{~K} 27 \mathrm{ac}{ }^{\mathrm{hi}}$ and $\mathrm{H} 3 \mathrm{~K} 4 \mathrm{me} 3{ }^{\text {hi }} \mathrm{H} 3 \mathrm{~K} 27 \mathrm{ac}{ }^{\text {hi }}$, respectively [17]. In contrast, repressive marks on enhancers, such as H3K27me3, indicate a poised status of activation, meaning that particular enhancer has the potential to be activated [17].

The combination of cell-specific TF and chromatin modifications shapes the epigenetic landscape of macrophages, thereby defining the spectrum of responses that these cells are capable of carrying out [17]. Each cell type possesses a unique enhancer landscape that allows them to carry out cell-specific functions [18]. To further illustrate the notion that cell functions are dependent on preestablished epigenetic patterns, Creyghton et al. showed that nuclear reprogramming of fibroblasts into fibroblast-derived induced pluripotent stem cells resets the global enhancer patterns to embryonic stem (ES) cell configuration [16]. Reciprocally, gains and losses of H3K27ac marks on genes expressed by differentiated neural cells were observed in comparison with ES cells and neural progenitors, which suggests that cell types alter their epigenetic landscape during differentiation [16].

After the establishment of the macrophage lineage by pioneer TF, some genes are additionally bound by secondtier TF, also referred to as "primers" [19]. Exemplified by Atf3, JunB, and AP-1, primer TF marks the potential of the cells to respond to environmental stimuli, and it is believed that they attract inflammation-related TF upon stimulation [19]. When macrophages are primed by an environmental cue, they need to respond rapidly and therefore acute chromatin remodelling is required (Figure 1(c)). PU.1 in combination with C/EBP is responsible for the induction of many LPSand TNF-responsive genes $[8,20]$. In addition, p300 and 


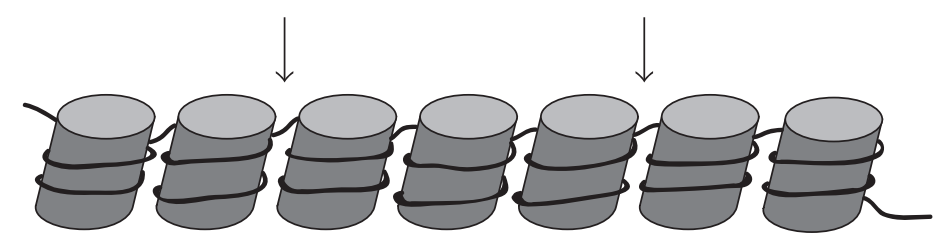

(a)

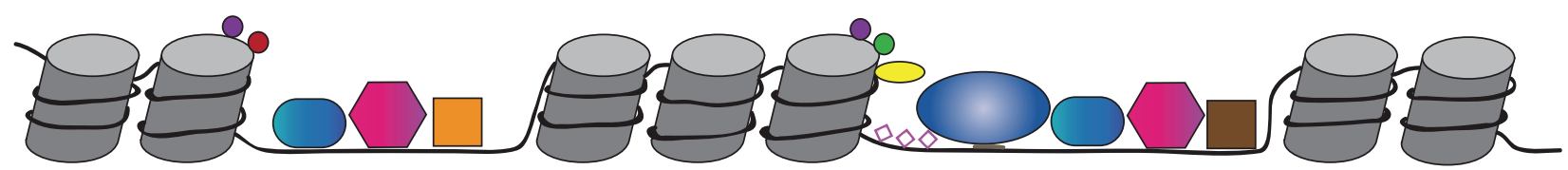

PU.1

$\mathrm{C} / \mathrm{EBP}$

Repressor complexes

Inflammation-related TF

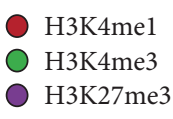

33K27me3
RNA polymerase II

p300

$\diamond \quad$ CpG island

(b)
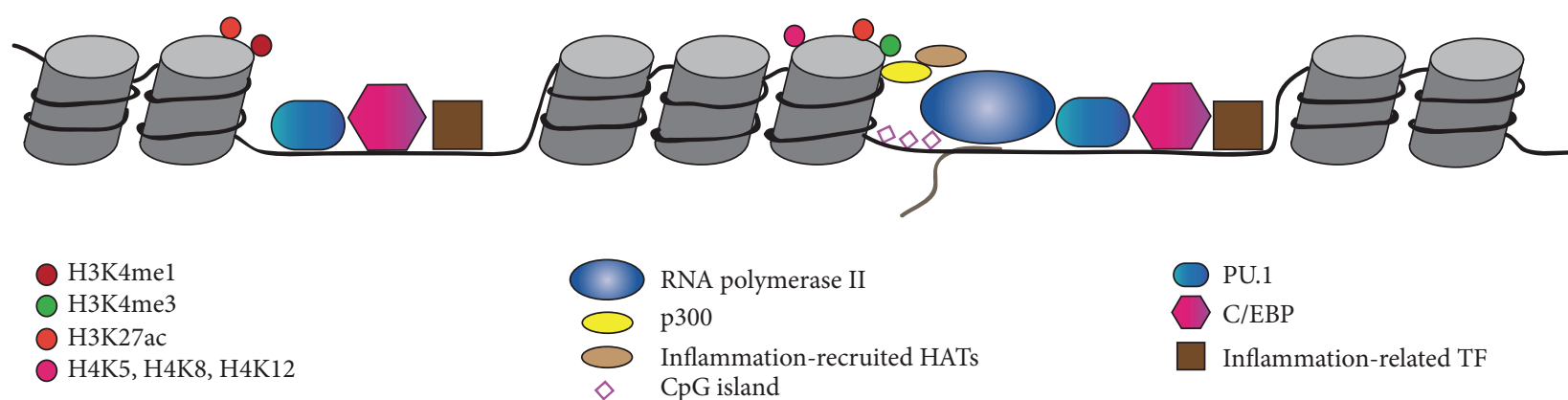

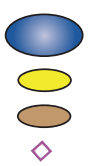

RNA
p300

Inflammation-recruited HATs CpG island

(c)

FIGURE 1: Epigenetic regulation in macrophages in homeostasis and inflammation. (a) During lineage establishment, the master macrophage regulator PU.1 unpacks the tight organisation of chromatin and binds to its motifs on the DNA sequence (arrows). Additional macrophagerestricted TFs interact with PU.1 and are subsequently recruited to the loosened DNA resulting in establishment of nucleosome-free regions at macrophage enhancers and promoters. (b) Enhancers are epigenetically marked by the H3K4mel signature, whereas promoters are H3K4me3 labelled. Genes which are not active at baseline may be poised, meaning that their enhancers are marked by H3K27me3 signatures, rendering them ready to promote gene transcription in the presence of an appropriate stimulus. One category of such genes is the primary response genes, which exhibit active repression at their enhancers and are transcribed at low levels. (c) In the presence of local signals, these genes lose the suppressive H3K27me3 mark on their enhancers and promoters and are acetylated at H3K27 by the constitutively present p300 and recruited acetyltransferases. The produced transcripts are successfully elongated and leave the nucleus for protein synthesis. This conversion is facilitated by inflammation-related TF, which bring enhancers close to gene promoters to initiate gene transcription.

other acetyltransferases $[21,22]$ are recruited to $\mathrm{H} 3 \mathrm{~K} 4 \mathrm{me} 1^{\text {hi }}$ enhancers, enriched at LPS-induced genes, where they acetylate $\mathrm{H} 3$ and $\mathrm{H} 4$ histones [11, 22]. The recruitment of inflammation-related TF to enhancers, such as NF-kB, IRF proteins, AP-1, and FOS, suggests that p300, together with the constitutively active PU.1 and recruited TF, regulates gene expression and immune responses of these myeloid cells [11]. For example, in IFN- $\gamma$-stimulated macrophages, STAT1 is recruited to selected $\mathrm{H} 3 \mathrm{~K} 4 \mathrm{me}{ }^{\text {hi }}$ enhancers and induces the expression of IFN- $\gamma$ responsive genes [18].

Gene activation kinetics upon TLR4 ligation revealed that the induced genes fall into two groups; the primary response genes, induced independently of new protein synthesis shortly after macrophage activation, and the secondary response genes, the expression of which is elevated many hours after ligation [23, 24]. Although both groups of genes have similar $\mathrm{H} 3 \mathrm{~K} 4 \mathrm{me} 3$ and $\mathrm{H} 3 \mathrm{~K} 9 / 14 \mathrm{ac}$ distribution on their promoters under basal conditions, the former exhibits increased RNA polymerase occupancy at their promoters and low levels of gene transcription $[9,25,26]$. In addition, the promoters of primary response genes are enriched for NF-kB, AP-1/CREB, and SRF factor motifs, whereas the secondary response genes possess interferon-sensitive response elements (ISREs) binding sites [9].

Elegant work by Ramirez-Carrozzi et al. provided an insight into the mechanistic framework of primary and secondary response gene expression in macrophages during LPS activation [27]. High CpG content in promoters of early primary response genes correlates with loosened conformation of chromatin. In contrast, genes that lack $\mathrm{CpG}$ island-rich promoters require further nucleosome remodelling by the SWI-SNF nucleosome remodeller in order to be expressed. 
Following LPS stimulation, H4K5, H4K8, and H4K12 are acetylated by $\mathrm{p} 300$ and the recruited acetyltransferases GCN5 and PCAF at both primary and secondary response gene promoters [25].

Recently, Ostuni et al. discovered another subset of enhancers termed latent enhancers, which are neither PU.1 nor $\mathrm{H} 3 \mathrm{~K} 4 \mathrm{mel}$ marked under basal conditions but are induced upon macrophage activation [28]. Latent enhancers induce late-transcribed genes and the TF they depend on for their expression varies according to the environmental stimulus responsible. Interestingly, the authors showed that removal of IFN- $\gamma$ and IL-4 retained the induced H3K4mel marks on the enhancers and preserved these elements in poised conformation [28].

The existence of epigenetic regulation of macrophages is not only essential for the induction of their activation and participation in the inflammatory process, but is also required for the inhibition of the immune response and avoidance of excessive inflammation and tissue damage [23]. Corepressor complexes, such as the NCoR, SMRT, CoREST, mSin3A, and $\mathrm{RCoR}$ or the CTCF factor, are recruited to gene promoters under the basal state and need to be displaced by coactivators of gene expression [21, 25]. Bcl-6 is a TF that controls expression of more than one-third of all LPS-responsive genes. It acts to antagonise NF-kB binding at enhancers and is essential for transcriptional repression [29]. During LPS stimulation, macrophage gene expression is tightly controlled by inducible signal- and gene-specific regulators, which aim to suppress gene expression at either the posttranscriptional or the posttranslational level [21].

The remainder of this review will discuss the epigenetic changes that occur upon activation of macrophages and influence polarisation to the M1 or the M2 phenotype. We focus particularly on the role of four broad families of enzymes that are responsible for altering the condensation of chromatin during inflammatory conditions, resulting in gene induction or suppression and how these enzymes interfere with the methylation and acetylation motifs at the promoters of genes to enhance or inhibit their transcription and dictate the overall responses of macrophages to various environmental stimuli.

\section{Activated Macrophages Acquire Different Polarisation States}

Macrophages are activated and respond to mount an effective immune response against potentially harmful agents, such as PAMPs, DAMPs, or tumours. The outcome of macrophage activation depends on the inflammatory stimulus. Historically, macrophage activation states have been summarised under the "M1/M2 paradigm." The M1/M2 paradigm comes as a reflection of the $\mathrm{T}_{\mathrm{H}} 1 / \mathrm{T}_{\mathrm{H}} 2$ paradigm of $\mathrm{T}$ helper cell activation and embodies the activation status of macrophages primed with IFN- $\gamma$, LPS, viral products, or GM-CSF (M1 macrophages or classically activated) or IL-4, IL-10, glucocorticoids, or M-CSF (M2 macrophages or alternatively activated). In many studies, M2 macrophages have been further divided into M2a (IL-4 induced), M2b (IgG induced), and M2c (IL-10 and glucocorticoid induced) despite the fact that a consensus has been reached to instead define macrophage phenotypes based on the activator used [81].

Induction of the M1 or M2 phenotype in macrophages is associated with a complex network of signalling intermediate effectors and TF. JNK, PI3K/Akt, Notch-Jagged, and cytokine-induced JAK/STAT pathways have all been implicated in skewing macrophage responses to one state or the other, leading to TF-mediated gene expression $[82,83]$.

Recently, microRNAs have been reported to play a pivotal role in macrophage polarisation and much attention has since focused on their indirect contribution to immunopathologies (reviewed in $[83,84]$ ). Some microRNAs have been associated with M1 macrophage functions, such as miR-29b, miR125-a-5p, and miR-155 [85], whereas others, such as miR-21, miR-146a, miR-155, miR-124, miR-223, and let-7c, have been linked to the M2 macrophage anti-inflammatory properties [86-92].

M1 activated macrophages acquire a proinflammatory phenotype and secrete high levels of IL-12 and IL-23 and $\mathrm{T}$ cell recruiting chemokines, such as CXCL9 and CXCL10, but low levels of IL-10. M2 activated macrophages secrete CCL17, CCL22, and CCL24 and IL-10 and express IL-1ra on their surface [93]. M1 macrophages are poised to kill intracellular pathogens and promote $\mathrm{T}_{\mathrm{H}} 1$ responses, whereas M2 macrophages clear parasitic infections and promote tissue remodelling. The two activation states can be characterised by certain markers. For example, Nos 2 and Il12 are referred to as M1 activation markers, with Arg1, Ym1, Fizzl, and $\mathrm{Mgl}$ assigned to the M2 class.

It is important to keep in mind that these polarisation states are not stable in vivo; macrophages display a high degree of plasticity, and activation states can often coexist or change during disease progression upon exposure to microenvironment nascent mediator release [81]. In support of this, human macrophages primed with a range of activation stimuli acquired a spectrum of activated phenotypes ranging from the classical to the alternative pathways with shared and specific transcriptional signatures [94].

The presence of polarised macrophages has been linked to pathologies in animal models [95]. Resembling the $\mathrm{T}_{\mathrm{H}}{ }^{1-}$ $\mathrm{T}_{\mathrm{H}} 2$ paradigm, $\mathrm{M} 1$ macrophages have been associated with antitumour activity [96], whereas M2 polarised macrophages have been described in models of asthma and parasite infection $[97,98]$. Interestingly, adipose tissue macrophages from lean mice have been reported to express M2 signature genes [99], whereas high fat diet induces the recruitment of bone marrow-derived macrophages, which express M1 markers and contribute to the pathology in the adipose tissue [100].

It is clear that, in order to pharmacologically intervene in diseases where macrophages play a fundamental role, there is a need to understand the mechanisms by which these cells acquire new phenotypes in vitro and in vivo.

\section{Histone Methyltransferases (HMTs)}

The domain that primarily catalyses lysine methylation is called Suppressor of variegation-Enhancer of zeste-Trithorax 
TABLE 1: HMTs and DNMT involved in macrophage polarisation.

\begin{tabular}{|c|c|c|c|}
\hline Name & Family & Function & References \\
\hline HMTs & - & $\begin{array}{l}\text { IL-6, IL-12, TNF- } \alpha \text {, NO secretion } \\
\text { induction, and IL- } 1 \beta \text { secretion inhibition }\end{array}$ & {$[30]$} \\
\hline SETDB1 & KMT1 & $T N F$ repression & {$[31]$} \\
\hline EHMT2 & KMT1 & If $n \beta$ and ISG suppression & {$[32]$} \\
\hline EHMT1, EHMT2 & KMT1 & M2-IL-4 activation status & [33] \\
\hline MLL & KMT2 & CXCL10 induction & {$[34]$} \\
\hline MLL4 & KMT2 & CD14 membrane anchoring & {$[35]$} \\
\hline Ash1 & KMT2 & A20 production and IL- 6 suppression & {$[36]$} \\
\hline $\begin{array}{l}\text { SETD1A, ASH1, } \\
\text { MLL3, and MLL4 }\end{array}$ & KMT2 & M2-IL-4 activation status & {$[33]$} \\
\hline SMYD2 & KMT3 & $\begin{array}{l}\text { Tnf, Il6, MHC-II, and CD40/80 } \\
\text { suppression }\end{array}$ & {$[37]$} \\
\hline SMYD3 & KMT3 & Alox15 induction & {$[34]$} \\
\hline SMYD5 & KMT3 & $I l 1 \alpha, I l 1 \beta, C c l 4, \operatorname{Tnf}$, and Cxcl10 repression & [38] \\
\hline $\begin{array}{l}\text { SUV } 420 \mathrm{H} 2 \text { and } \\
\text { SETD8 }\end{array}$ & KMT5 & M2-IL-4 activation status & {$[33]$} \\
\hline EZH1 & KMT6 & M2-IL-4 activation status & {$[33]$} \\
\hline DNMT & - & $\begin{array}{c}\text { Cfb, Serping, Tnfsf15 induction } \\
\text { Arg1, Nrp1, Cxcr4, Plxnd1, Cdk18, and Fes } \\
\text { repression }\end{array}$ & [39] \\
\hline DNMT1 & - & Socs1 silencing & {$[40]$} \\
\hline $\begin{array}{l}\text { DNMT1 and } \\
\text { DNMT3b }\end{array}$ & - & Cystathionine- $\gamma$-lyase suppression & {$[41]$} \\
\hline DNMT3B & - & $\begin{array}{c}\text { PPAR- } \gamma \text { silencing and polarisation to } \mathrm{M} 1 \\
\text { phenotype }\end{array}$ & {$[42]$} \\
\hline $\begin{array}{l}\text { DNMT3A and } \\
\text { DNMT3L }\end{array}$ & - & M2-IL-4 activation status & {$[33]$} \\
\hline
\end{tabular}

(SET) and additional protein sequences define HMTs into eight distinct subfamilies. KMT2, KMT3, and KMT7 subfamily members leave positive marks on H3K4 and H3K36, whereas KMT1, KMT5, KMT6, and KMT8 leave repressive marks on H3K9, H4K20, and H3K27. KMT4 is the only HMTs subfamily with no SET domain and is responsible for H3K79 methylation. SET7/9 can additionally methylate nonhistone proteins, such as p53, NF-kB, DNA methyltransferase 1, and others [14].

Changes in histone conformations have been extensively reported to occur during priming of macrophages with LPS, IL-4, and IFN- $\gamma$ [101]. Epigenetic effects on histones cause the formation of DNA loops that bring together distant chromatin sequences and regulate transcription. Innate (e.g., MARCO, CD200, and CD200R1), classical (e.g., H2-Eb1), and alternative (e.g., MRC1) activation markers are some of the genes readily affected resulting in macrophage polarisation [101].

Macrophage polarisation is differentially regulated by different KMT subfamilies and in some cases by different members within one subfamily (Figure 2(a)). HMTs may switch on the expression of genes, such as cytokine and NO expression [30], or suppress gene expression by methylating negative histone tails. In general terms, HMTs promote polarisation of macrophages towards the M2 phenotype (Table 1). For instance, trimethylation of H3K9 by the KMT1 member SETDB1 silences TNF transcription [31], whereas dimethylation of $\mathrm{H} 3 \mathrm{~K} 9$ results in Ifn and downstream interferonstimulated gene (ISG) suppression in dendritic cells (DCs) and macrophages [32].

The KMT2 members are among the most well-studied HMTs and are associated with M1 macrophage polarisation. The expression of MLL is enhanced in M1 polarised human macrophages and is responsible for $\mathrm{H} 3 \mathrm{~K} 4$ trimethylation of signature gene promoters, such as CXCL10 [34]. In contrast, other KMT2 members induce the transcription of inflammation inhibitory genes, most likely to modulate or even terminate macrophage responses. For example, Ash1 trimethylates the Tnfaip3 promoter to induce the expression of the TLR-antagonising protein A20, which then suppresses IL-6 secretion by peritoneal macrophages [36].

HMTs can also interfere with upstream macrophage activation signalling. Genetic deletion of MLL4 is linked to impaired CD14 surface expression on LPS-stimulated macrophages. Austenaa et al. demonstrated that Pigp, an essential component of the GPI-GlcNAc transferase, is one 

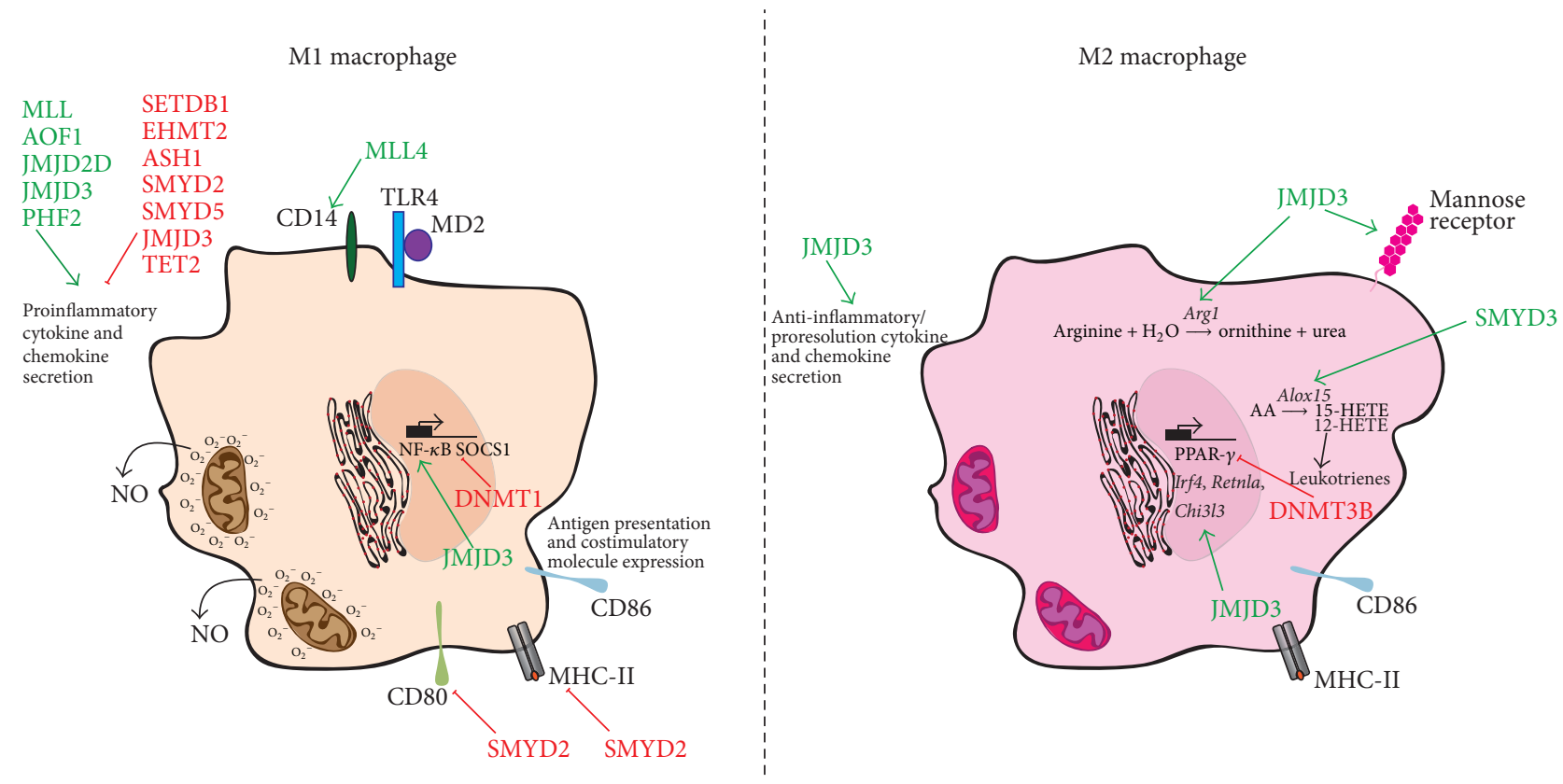

(a)
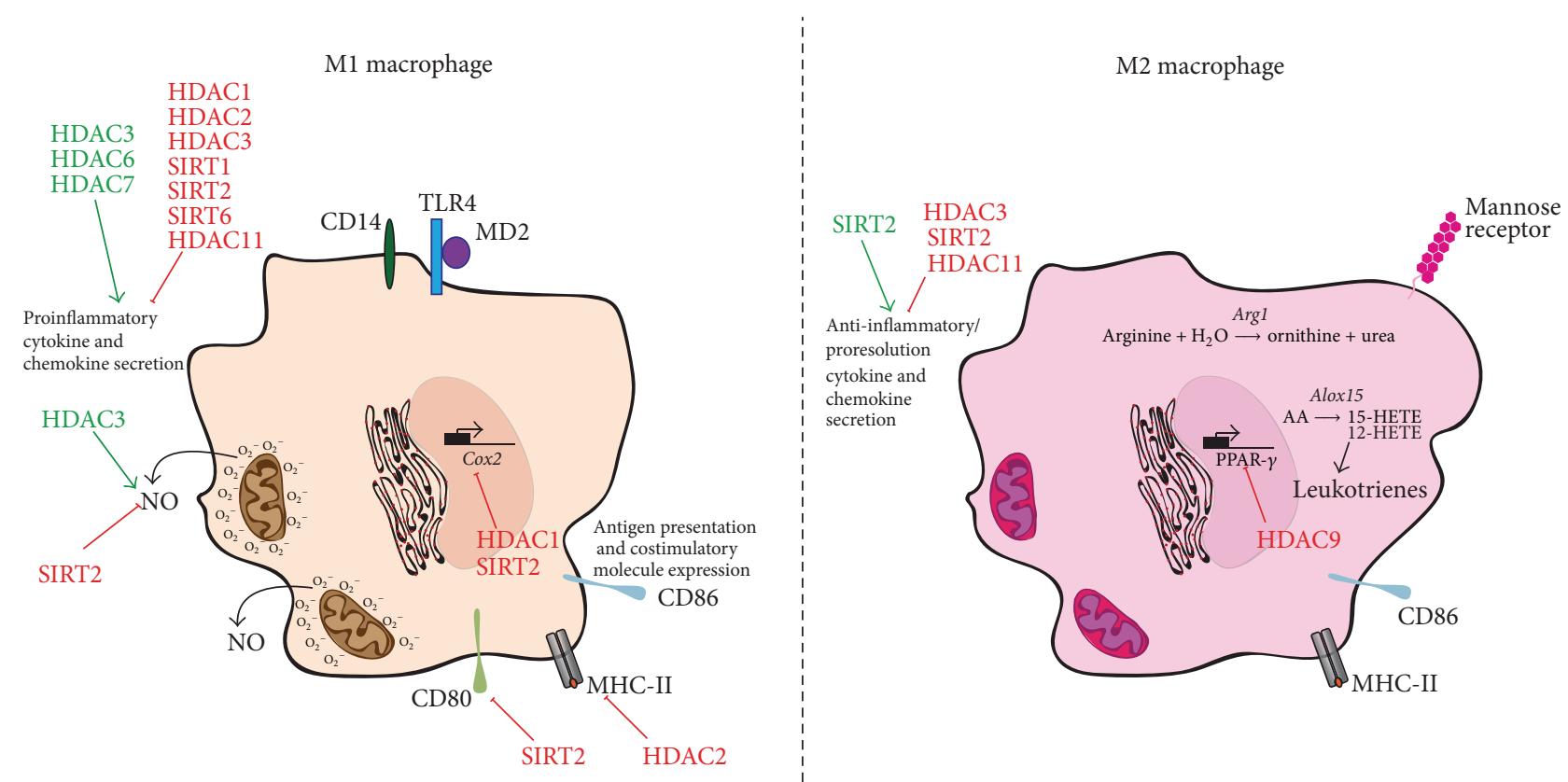

(b)

FIGURE 2: Histone methylation and acetylation status affect gene expression and macrophage polarisation to the M1 or the M2 phenotype. (a) HMTs induce the secretion of proinflammatory cytokines and chemokines in the cell microenvironment and stabilise the levels of CD14 on the macrophage surface. In contrast, some HMTs suppress the expression of MHC-II and costimulatory molecules and modulate the secretion of proinflammatory mediators. These enzymes contribute significantly to the M2 state, inducing the expression of M2 signature markers and the secretion of anti-inflammatory cytokines. (b) Although histone acetylation by HATs is generically associated with gene expression initiation, HDACs can skew the phenotype of macrophages equally to the M1 or the M2 phenotype. Depending on the HDACs subfamily, these enzymes have been shown to affect proinflammatory/proresolution cytokine secretion, MHC-II and costimulatory molecule expression, secretion of ROS and NO, and control of polarisation-determining TF, arachidonic acid (AA), and 12-hydroxyeicosatetraenoic acid (12-HETE). 
TABLE 2: DMTs involved in macrophage polarisation.

\begin{tabular}{|c|c|c|c|}
\hline Name & Family & Function & References \\
\hline AOF1 & KDM1 & $M d c, I l 12 b$, and $I p 10$ induction & {$[43]$} \\
\hline KDM2A & KDM2 & M2-IL-4 activation status & [33] \\
\hline JMJD2D & KDM4 & $I l 12 b$ and $M d c$ induction & {$[44]$} \\
\hline JMJD3/UTX & KDM6 & TNF- $\alpha$ secretion & {$[45]$} \\
\hline JMJD3 & KDM6 & NF-kB, CD40, and IFN signalling & {$[46]$} \\
\hline JMJD3 & KDM6 & IL-12/IL-10 increase & {$[47]$} \\
\hline JMJD3 & KDM6 & Il12b, Il23a, G-CSF, and Trem 1 induction & {$[48]$} \\
\hline JMJD3 & KDM6 & Arginase-1, CD206 induction, TNF- $\alpha$, and IL- 6 repression & [49] \\
\hline JMJD3 & KDM6 & Arg1, Retnla, and Chi3l3 induction & {$[50]$} \\
\hline JMJD3 & KDM6 & Arg1, Fizzl, Ym1, Mrcl, and Il13 induction & {$[51]$} \\
\hline JMJD3 & KDM6 & Irf4 induction & {$[49,51]$} \\
\hline PHF2 & KDM7 & Tnf, Ccl4, Cxcl10, Illa, Illb, Il6, Ccl5, Irf1,Mxl, and Oas3 induction & [38] \\
\hline TET2 & TET & Il6 repression & {$[52]$} \\
\hline
\end{tabular}

of several hypomethylated genes following MLL4 ablation in macrophages, leading to defective CD14 GPI-anchoring on the cell surface [35].

KMT3 enzymes have been reported to contribute to M2 polarisation. LPS-stimulated macrophages downregulate SMYD2 to prevent the H3K36 dimethylation-mediated repression of Tnf, Il6, MHC-II, and CD40/80 expression [37]. Another member of this family, SMYD3, is overexpressed in M2 polarised macrophages and is responsible for alternative activation epigenetic remodelling, such as H3K4 trimethylation of ALOX15 [34]. Acting on a different lysine residue, SMYD5 reversibly trimethylates $\mathrm{H} 4 \mathrm{~K} 20$ to shut down transcription of LPS-induced genes, such as Tnf and Cxcl10 [38].

\section{DNA Methyltransferases (DNMTs)}

In addition to histone methylation, DNMT enzymes carry out DNA cytosine methylation and are divided into four distinct families: DNMT1, DNMT2, DNMT3 (consisting of DNMT3a, DNMT3b, and DNMT3L), and the chromomethylase family, which is exclusive to plants [102].

DNA methylation occurs in intragenic, intergenic, and CpG islands in promoter regions in mammals [103]. Methylation of promoters leads to gene expression silencing, whilst methylation of intragenic regions can induce the expression of alternative transcripts which are tissue- and cell-specific [103]. The presence of numerous hypomethylated regions in intragenic and intergenic regions in macrophages is associated with gene expression in these cells, underlining the influence of global methylation on gene expression [104].

DNA methylation of $\mathrm{CpG}$ islands in gene promoters has been shown to shift macrophages towards both M1 and M2 phenotypes by inactivating state-specific signature genes. Methylation of $\mathrm{CpG}$ islands impacts negatively on the expression of genes. For example, DNMT1 hypermethylates SOCS1 gene promoter during LPS activation of macrophages and prolongs the secretion of proinflammatory mediators, such as TNF- $\alpha$ and IL-6 [40]. Hypermethylation of gene promoters by DNMT1 and DNMT3b exacerbates the outcome in an experimental model of atherosclerosis by repressing the expression of cystathionine- $\gamma$-lyase [41].

Genome-wide methylated DNA sequencing of recruited macrophages in ischemic muscles of hyperlipidemic and type 2 diabetes mellitus mice revealed that $C f b$, Serping, and Tnfsf15 promoters were hypomethylated, whilst Arg1, Nrp1, Cxcr4, Plxnd1, Cdk18, and Fes were significantly hypermethylated in inflamed tissues, skewing macrophage phenotype to the M1 lineage [39].

Similarly, DNMT3B is activated in adipose tissue macrophages of obese mice and silences the M2 TF PPAR- $\gamma$ via methylation of $\mathrm{CpG}$ sites on its promoter [42]. Additional supporting evidence comes from atherosclerosis studies, where inhibition of DNA methyltransferases in macrophages results in a severe reduction in migration to plaques, adhesion to the endothelium, and secretion of a broad range of proinflammatory cytokines, chemokines, and adhesion molecules [105]. LXR $\alpha$ and PPAR- $\gamma$ CpG sites were shown to be hypomethylated providing a possible explanation for the anti-inflammatory phenotype of macrophages.

\section{Histone Demethylases (DMTs)}

In contrast to HMTs, DMTs enzymes remove methyl groups from histones exhibiting dynamics of chromatin remodeling and constant regulation of gene expression. There are seven subfamilies of DMTs with high specificity for their substrates (Table 2). H3K4 mono- and dimethylation are removed by KDM1 members, but KDM2, KDM5, and KDM6 members can also demethylate H3K4 [14]. H3K9 mono- and dimethylation are reversed by KDM3 and KDM7 subfamily members, whereas KDM4 were the first proteins identified to catalyse removal of di- and trimethylation from histones. The negative marks on H3K36 tails are removed by KDM2 (mono- and dimethylation) and KDM4 (di- and trimethylation). Finally, di- and trimethylation on H3K27 are demethylated by KDM6, whereas mono- and dimethylation on H3K27 are removed by KDM7 [14].

DMTs modulate polarisation of macrophages to both M1 and M2 states (Figure 2(a)). The KDM1 member AOF1 
was shown to be recruited by c-Rel to Il12b, $M d c$, and Ip10 promoters in DCs and macrophages stimulated with LPS [43]. Recruited AOF1 demethylates $\mathrm{H} 3 \mathrm{~K} 9 \mathrm{me} 2$ and is involved in a feed-forward circuit to attract more NF-kB molecules and initiate the transcription of proinflammatory genes [43]. Similarly, the KDM4 family member JMJD2D was reported to attack H3K9me3 levels around the enhancers of $I l 12 b$ and $M d c$ genes in DCs and macrophages upon stimulation with LPS and release them from active repression [44].

The most widely studied demethylase in the macrophage polarisation field is the KDM6 member, JMJD3. JMJD3 has been reported to affect multiple cellular processes under inflammatory conditions in macrophages, such as transcription of inflammatory genes, oxidative stress, chromatin remodelling, cell proliferation, and differentiation [106]. JMJD3 expression is rapidly upregulated in LPS-activated microglia through existing NF-kB molecules, STAT1/STAT3 $[107,108]$ and together with the other KDM6 member, UTX, it contributes to the establishment of the M1 phenotype by tuning gene transcription early on after stimulation [109], before removing methyl groups from H3K27me3-repressed M1 signature genes, such as TNF [45]. JMJD3's role was demonstrated in an in silico study, where it was predicted to target the CD40, chemokine, and IFN signalling pathways [46]. Another line of evidence suggests that in human type 2 diabetes nonhealing wounds and diet-induced obese mice, JMJD3 is responsible for the elevated IL-12/IL-10 ratio [47] and it has also been reported to be expressed in serum amyloid A-primed murine macrophages as part of the proinflammatory cytokine secretion program [48].

In contrast, other reports have shown that deficiency of JMJD3 in microglia leads to enhanced proinflammatory mediator secretion, such as TNF- $\alpha$ and IL-6, and a reduction in the M2 markers, Arginase-1, and CD206, creating a hostile microenvironment for neurons [49]. This result suggests that JMJD3 may also be induced by alternative activation. Indeed, JMJD3 is expressed in IL-4-stimulated BMDM as a direct downstream target of STAT6 [50] and promotes the expression of Irf4 to establish a M2 phenotype [51].

Recently, a novel family of $\mathrm{Fe}^{2+}$ - and 2-oxoglutaratedependent dioxygenases [110], named ten-eleven translocation (TET) proteins (reviewed in [111]), were found to take part in a number of biological processes, such as embryonic development [112] and epigenetic regulation of gene transcription and cancer [113], and mediate their effects by oxidising 5-methylcytosine in DNA to 5-hydroxymethylcytosine, 5formylcytosine, and 5-carboxylcytosine [114, 115].

Although TET2 and TET3 are expressed in macrophages, their levels are not increased upon LPS stimulation, implying that they may not play a critical role in DNA demethylation during macrophage activation [116]. However, Zhang et al. showed that TET2 actively represses IL- 6 during the resolution phase of inflammation [52]. The authors found that IkB $\zeta$ targets TET2 to the Il6 promoter to indirectly recruit HDAC2, which deacetylates $\mathrm{H} 3$ and $\mathrm{H} 4$ histones and suppresses transcription.

Therefore, TET enzymes warrant further investigation as they may regulate macrophage polarisation either directly
TABLE 3: HATs involved in macrophage polarisation.

\begin{tabular}{lcc}
\hline Target & Function & References \\
\hline H3K9/14 & $\begin{array}{c}\text { TNF- } \alpha \text {, IL-6, NOS2, } \\
\text { MHC-II, and CIITA } \\
\text { induction } \\
\text { H3 }\end{array}$ & $\begin{array}{c}\text { IFNA, TNF, and IL6 } \\
\text { expression }\end{array}$ \\
\hline
\end{tabular}

through conversion of cytosines in gene promoter DNA sequences or indirectly via recruitment of histone modifying enzymes.

\section{Histone Acetyltransferases (HATs)}

Histone acetyltransferases are enzymes that transfer acetyl groups to core histones, which has subsequent effects on chromatin remodelling and gene expression. They are a diverse group of proteins with several catalytic domains that dictate their subunit specificity and functions. HATs are divided into two families [117]: Gcn5 N-acetyltransferases (GNATs) and Morf, Ybf2, Sas2, and Tip60 HATs. Other proteins, such as $\mathrm{p} 300 / \mathrm{CBP}$, Tafl, and nuclear receptor coactivators also possess catalytic acetyltransferase activities, but no typical HATs domains. These proteins are considered as an orphan class of HATs [117].

HATs have been shown to be involved in initiating gene expression in macrophages during inflammation (Table 3). However, to date only a limited number of reports have detailed how HATs catalyse the expression of specific M1 or M2 associated genes. Instead, we only have a more global understanding of histone acetylation and its role in regulating gene expression.

Soluble/secreted factors from the parasite $M$. corti were shown to downregulate Tnf, Il6, Nos2, H2-Eb1, and Ciita expression in LPS-primed microglia. These factors suppressed $\mathrm{H} 3 \mathrm{~K} 4 \mathrm{me} 3$ and $\mathrm{H} 3 \mathrm{~K} 9 / 14 \mathrm{Ac}$ in these genes and promoted RNA polymerase II recruitment to the Argl promoter, causing compromised immune responses of microglia in murine neurocysticercosis [53].

HATs may also interact with the opposing histone deacetylase enzymes to enhance acetylation and eventually activation of antiviral gene promoters. For example, p300/CBP was shown to be recruited to the inactive Ifn $\alpha$ promoter upon IRF5 phosphorylation and displace the SMRT/Sin3a repressive complexes. IRF5 is subsequently acetylated by p300/CBP facilitating $\mathrm{H} 3$ histone acetylation of target genes, including Tnf and Il6 [54].

\section{Histone Deacetylases (HDACs)}

The enzymes that oppose HATs functions are referred to as HDACs. Histone deacetylation is a dynamic process and may be the result of other posttranslational modifications. HDACs functions may induce further epigenetic changes and alternative gene expression (Table 4). To date there have been eighteen identified mammalian HDACs, which are classified in five groups: Class I (HDAC1, HDAC2, HDAC3, 
TABLE 4: HDACs involved in macrophage polarisation.

\begin{tabular}{|c|c|c|c|}
\hline Name & Class & Function & References \\
\hline- & Classes I and II & $\begin{array}{l}\text { Pattern recognition receptors, activation } \\
\text { markers, cytokines, chemokines, secretion of } \\
\text { reactive oxygen species, and NO induction }\end{array}$ & {$[30,55-57]$} \\
\hline- & Classes I and II & MIF induction & [58] \\
\hline- & Classes I and II & $\begin{array}{l}C d 16 \text { induction, } C d 206, \text { TNF- } \alpha \text {, and NO } \\
\text { repression }\end{array}$ & {$[59]$} \\
\hline- & Classes I and II & PU.1 induction & {$[60,61]$} \\
\hline- & Classes I and II & Argl induction & {$[62]$} \\
\hline- & Class I & $\begin{array}{l}\text { IL-12, TNF- } \alpha \text { secretion, IL-10 repression, } \\
\text { and CD } 40 / 80 \text { induction }\end{array}$ & [63] \\
\hline HDAC1 & Class I & IFNA and IL6 repression & {$[54]$} \\
\hline HDAC1 & Class I & Cox2, Pail inhibition, and $E d n 1$ induction & {$[64]$} \\
\hline HDAC2 & Class I & Ciita inhibition & {$[65]$} \\
\hline HDAC2 & Class I & M2-IL4 activation status & [33] \\
\hline HDAC2 & Class I & Il6 repression & {$[52]$} \\
\hline HDAC3 & Class I & IFN- $\beta$ secretion & {$[66]$} \\
\hline HDAC3 & Class I & TGF- $\beta$ suppression & {$[67]$} \\
\hline HDAC3 & Class I & IL-6, NO secretion & {$[30]$} \\
\hline HDAC6 & Class IIb & $E d n 1$ and $I l 12 b$ induction & {$[64]$} \\
\hline HDAC7 & Class IIa & $I l 12 b, I l 6$, and $E d n 1$ induction & {$[68]$} \\
\hline HDAC9 & Class IIa & PPAR- $\gamma, A B C A 1$, and ABCG1 repression & {$[69]$} \\
\hline HDAC9 & Class IIa & M2-IL4 activation status & {$[33]$} \\
\hline SIRT1 & Class III & Tnf, Il6, Nos2, and Mcp1 represion & {$[70]$} \\
\hline SIRT1 & Class III & $\begin{array}{l}\text { TNF- } \alpha \text {, IL- } 1 \beta \text {, IL- } 6 \text {, IL-12, and MCP-1 } \\
\text { inhibition }\end{array}$ & [71-73] \\
\hline SIRT1 & Class III & $\mathrm{PGE}_{2}$ inhibition & {$[74]$} \\
\hline SIRT1 & Class III & M2-IL4 activation status & {$[33]$} \\
\hline SIRT2 & Class III & $\begin{array}{l}\text { Tnf, Il6, Mcp1 repression, } I l 4 r \text {, and } I l 10 \\
\text { induction }\end{array}$ & {$[75]$} \\
\hline SIRT2 & Class III & $\begin{array}{l}\text { Tnf, Ill } \beta, I l 6, \operatorname{Cox} 2, \text { Nos } 2 \text {, and reactive } \\
\text { oxygen species inhibition }\end{array}$ & {$[76]$} \\
\hline SIRT2 & Class III & $\begin{array}{l}\text { iNOS, TNF- } \alpha \text {, IL- } 6 \text {, CD } 40 / 80 \text {, IL-10, and } \\
\text { reactive oxygen species inhibition }\end{array}$ & {$[77]$} \\
\hline SIRT6 & Class III & Ill $\beta$ repression & {$[72]$} \\
\hline HDAC11 & Class IV & Illo downregulation & {$[78,79]$} \\
\hline HDAC11 & Class IV & IL- $1 \beta$ repression & {$[80]$} \\
\hline
\end{tabular}

and HDAC8), Class IIa (HDAC4, HDAC5, HDAC7, and HDAC9), Class IIb (HDAC6 and HDAC10), and Class III (consists of the $\mathrm{NAD}^{+}$-dependent HDACs) and HDAC11, which constitutes a class of its own [118].

HDACs effects during macrophage activation (Figure 2(b)) have primarily been studied through the use of small molecule inhibitors [119]. For example, inhibition of histone deacetylases with the HDACs classes I and II inhibitor Trichostatin A (TSA) in differentiating bone marrow cells arrests cells to the phase of proliferating progenitors. [60]. Furthermore, simultaneous inhibition of HDACs classes I and II in several macrophage populations results in reduced levels of pattern recognition receptors, activation markers, cytokines, and chemokines. Secretion of reactive oxygen species, NO, and modulation of cellular processes, such as chemotaxis, phagocytosis, apoptosis, and cellular metabolism, have also been reported to be affected [30, 55-57]. In a study by Lugrin et al., the authors showed that the proinflammatory mediator macrophage inhibitory factor (MIF) is a downstream target of HDACs inhibition [58]. Inhibition of HDACs may also be beneficial in a complex inflammatory environment, whereby the interactions of macrophage populations with other resident cells are detrimental to the host. In this respect, HDACs inhibition rescued oligodendrocytes during traumatic brain injury via induction of the M2 phenotype in resident microglia [59].

There are many plausible explanations for the HDACs class I and II effects on macrophage activation status. Roger 
et al. reported that HDACs inhibition enhances the recruitment of the repressive complex Mi-2b to the promoters of M1 activation state genes, such as $I l 6$ [55]. Another possibility is that these effects are a result of the decline in the PU.1 levels in macrophages treated with TSA $[60,61]$. Interestingly, Serrat et al. proposed that TSA induces an acetylation-mediated repression on $\mathrm{C} / \mathrm{EBP} \beta$, which binds with lower efficiency to the Arg1 promoter in macrophages [62].

Use of a selective class I HDACs inhibitor, valproic acid (VPA), has been shown to reduce expression of M1-associated genes in macrophages, including CD40, CD80, and proinflammatory cytokines [63], implying that the members of this subfamily promote $\mathrm{M} 1$ activation in macrophages. Indeed, HDAC1, HDAC2, and HDAC3 were shown to act as a network of enzymes, aiming to enhance LPS-responsiveness in macrophages. Strikingly, this effect is mediated not only by histone tail modulation, but also via nonhistone protein phosphorylation and acetylation $[120,121]$.

Class I HDAC1 releases the IFNA promoter from bound repressive complexes upon interaction with p300/CBP and subsequent acetylation and transcription initiation [54]. Halili et al. expanded our understanding of this enzyme's actions. The authors reported that a HDAC1 inhibitor increased the expression of Cox 2 and Pail and reduced Edn1, indicating that $\mathrm{HDACl}$ may have a protective role in inflammatory diseases [64]. HDAC2 was reported to deacetylate and therefore modulate Ciita expression in macrophages [65]. In atherosclerotic plaques, such an effect may prove to be protective; CIITA promotes expression of MHC-II and antigen presentation to $\mathrm{T}$ cells, a pivotal step in transition to chronic inflammation, whilst inhibition of CIITA rescues collagen deposition by smooth muscle cells and eliminates plaque vulnerability.

Studies of HDAC3 demonstrate that it promotes macrophage responsiveness to LPS via IFN- $\beta$ production [66]. This deacetylase can lead to enhanced IL- 6 and NO secretion and inhibition of TGF- $\beta$ in an atherosclerosis model [30, 67], whereas HDAC3's proinflammatory effects in macrophages reflect its ability to bind to PU.1 and inhibit H3K9 acetylation in M2 signature genes [122].

Class IIa HDACs have also been shown to promote an M1 phenotype. In particular, a HDAC7 isoform that lacks the N-terminal 22 amino acids was reported to interact with the newly transcribed hypoxia-inducible factor 1-alpha and induce the expression of Il12b, Il6, and Edn1 in TLR4stimulated macrophages [68]. Another member, HDAC9, is associated with disease progression in $\mathrm{LDLR}^{-/-}$mice. Deletion of this histone modifier resulted in improved levels of HDL and LDL due to ABCA1 and ABCG1 upregulation and macrophage polarisation to the M2 phenotype [69]. In a recent report, HDAC6 inhibitors were shown to induce the expression of $E d n 1$ and $I l 12 b$ [64]. However, the authors concluded that HDAC6 might not work alone as HDAC6 ${ }^{-/-}$ BMDM showed normal LPS-induced expression of HDACsdependent genes.

Studies with the Class III HDACs have revealed that members of this enzyme subfamily behave diversely. SIRT1 levels in macrophages are dampened under inflammatory conditions, suggesting that this HDACs and the epigenetic changes it is responsible for are not required for cell activation [71]. Indeed, studies have shown that SIRT1 deficiency in myeloid cells results in increased tissue infiltration of M1 macrophages and augments inflammatory responses, mainly due to NF-kB p65, AP-1, and FAK increased acetylation and increased target gene expression [70, 72-74]. In $\mathrm{ApoE}^{-/-}$mice, haploinsufficiency of SIRT1 led to augmented macrophage oxLDL uptake and increased foam cell formation [123].

Deficiency of another member of the Sirtuin family, SIRT2, exacerbated DSS colitis in mice, exemplified by higher TNF- $\alpha$ and IL-1 $\beta$ levels, and impaired epithelial integrity [75]. Subsequent reports confirmed that SIRT2 deficiency increased the expression of proinflammatory genes, reactive oxygen and nitrite species, and activation surface markers in microglia and macrophage cell lines [76, 77]. Interestingly, SIRT2 has been shown to act as an NF-kB p65 deacetylase, placing microglia inflammatory responses under control. Phosphorylation on serine 331 inactivates SIRT2 and allows cells to undergo a proinflammatory cycle, which ultimately leads to death and neurotoxicity in the CNS [77].

Sirtuins can form a complex network of enzymes acting in concert to regulate inflammatory responses initiated by macrophages. Strikingly, SIRT6 was shown to compensate for the loss of SIRT1 in macrophages by controlling the $I k B$ promoter acetylation status and subsequent Il1 $\beta$ expression [72].

The functions of the only HDACs Class IV member are only now being unravelled. A couple of reports found that $\mathrm{HDAC11}$ regulates the IL-12/IL-10 ratio in antigen presenting cells $[78,79]$. HDAC11 was found to bind to the proximal site of the IL-10 promoter and modulate the recruitment of PU.1, Sp1, and STAT3 at late stages of LPS activation. Given the pivotal role of IL-12 and IL-10 in T cell activation and tolerance, this enzyme holds a lot of promise in therapeutic intervention, where manipulation of the adaptive immune response is of critical importance [79]. Another role attributed to HDAC11 was IL- $1 \beta$ suppression in DCs and macrophages during LPS stimulation [80]. In fact, HDACs inhibition led to upregulation of IL- $1 \beta$ cleavage and maturation in a caspase 8-dependent manner, demonstrating that HDACs inhibition may prove to be more challenging than originally thought.

\section{Concluding Remarks}

Research in the field of epigenetic regulation of macrophages during inflammation has flourished in the last decade. We now know that methylation and acetylation sites on core histones adjacent to inflammation-related genes are heavily affected by epigenetic enzymes, which contribute to the establishment and maintenance of M1 or M2 phenotypes and therefore dictate the magnitude and type of immune response mounted.

HMTs are strongly associated with M2 activation by repressing M1 phenotype signature genes and promoting the transcription of M2 genes. Repression may occur in the basal 
state or during inflammation. In contrast, DMTs have been linked with the M1 phenotype as a result of demethylation of repressive sites on histones. These findings imply that although demethylation of core histones can be mainly linked to derepression of genes, methylation can be associated with both gene expression when it is positive (e.g., H3K4) or inhibition when negative (e.g., H3K9 and H3K27). However, the timing of histone methylation/demethylation in close proximity to gene promoters is crucial.

Accumulation of the negative $\mathrm{H} 3 \mathrm{~K} 9 \mathrm{me} 2$ motif at primary response gene promoters is sufficient to actively suppress transcription initiation [32]. Whether HMTs are recruited to gene promoters as a result of corepressor complexes is a common question that has been posed in recent reports and suggests that the level of gene regulation is complex and may outweigh a model of random attraction of these enzymes to gene promoters [38].

In fact, negative regulation of gene expression may involve networks of HMTs and corepressor complexes that work cooperatively to control the derepression of a cluster of primary response genes. In accordance with this, a different level of cell-specific and stimulus-induced gene repression in DCs and macrophages was shown to be achieved by deposition of $\mathrm{H} 3 \mathrm{~K} 9 \mathrm{me} 3$ at upstream broad enhancers of inflammation-related genes [44]. This method of gene repression seems to confer cell type-specific protection from excessive secretion of proinflammatory mediators in the basal state and the transcriptional constraints can be applied to various genes simultaneously [44].

As a generic model, it seems plausible to hypothesise that HMTs need guidance by a "molecular beacon" at the promoter DNA sequence in order to bind and methylate their substrates. This can be mediated by corepressor complexes, such as NcoR, SMRT, and $\mathrm{mSin} 3 \mathrm{~A}$, as described earlier, that provide the anchor sites for the HMTs adjacent to gene promoters and enhancers. Further investigation into the patterns of interactions between corepressor complexes and HMTs is needed and might reveal that gene regulation in macrophages in the basal state is not as random as it may seem and might be heavily dependent on the corepressor/activator complex balance at gene promoters.

Proinflammatory mediator expression during inflammation may be downregulated either by negative methylation effects of recruited HMTs at gene promoters or indirectly via positive methylation (and transcription initiation) of M2 signature or anti-inflammatory genes [36]. Hence, the assessment of HMTs and DMTs in macrophage polarisation needs to take into account indirect effects of these enzymes on genes, such as TFs that actively bind to the target gene promoters and drive the response to the M1 or the M2 phenotype.

To conclude, the epigenetic changes that occur in macrophages during activation by various environmental stimuli have attracted much interest. The strategic location of macrophage populations complemented by the ability to shape their functions according to the needs of the host makes the enzymes responsible for their polarisation, a potential target for therapeutic interventions. Although there are still many open questions regarding the mode of action and the interactions of these enzymes, the knowledge we have acquired over the last decade hints for more effort to understand the molecular pathways involved in the regulation of gene expression of macrophages during inflammation and the design of therapies to tackle acute and chronic inflammatory diseases.

\section{Abbreviations}

AA: Arachidonic acid

DAMPs: Danger-associated molecular patterns

DCs: Dendritic cells

DNMT: DNA methyltransferase

DMTs: Histone demethylases

ES cell: Embryonic stem cell

GNATs: Gcn5 N-acetyltransferases

HATs: Histone acetyltransferases

HDACs: Histone deacetylases

HETE: Hydroxyeicosatetraenoic acid

HMTs: Histone methyltransferases

ISREs: Interferon-sensitive response elements

ISG: Interferon-stimulated gene

MIF: Macrophage inhibitory factor

PAMPs: Pathogen-associated molecular patterns

SET: $\quad$ Suppressor of variegation-Enhancer of zeste-Trithorax

TET: Ten-eleven translocation

TF: Transcription factor

TSA: Trichostatin A

VPA: Valproic acid.

\section{Competing Interests}

The authors declare that they have no competing interests.

\section{Acknowledgments}

This work was supported by the British Heart Foundation Grant (RG/15/10/31485) and the EPA Research Fund. The authors would like to thank Professor David R. Greaves and Mr. Lewis Taylor for extensive reading and comments on the paper.

\section{References}

[1] P. J. Murray and T. A. Wynn, "Protective and pathogenic functions of macrophage subsets," Nature Reviews Immunology, vol. 11, no. 11, pp. 723-737, 2011.

[2] C. Varol, A. Mildner, and S. Jung, "Macrophages: development and tissue specialization," Annual Review of Immunology, vol. 33, pp. 643-675, 2015.

[3] L. C. Davies, S. J. Jenkins, J. E. Allen, and P. R. Taylor, “Tissueresident macrophages," Nature Immunology, vol. 14, no. 10, pp. 986-995, 2013.

[4] D. Gosselin, V. M. Link, C. E. Romanoski et al., "Environment drives selection and function of enhancers controlling tissuespecific macrophage identities," Cell, vol. 159, no. 6, pp. 13271340, 2014. 
[5] E. L. Gautiar, T. Shay, J. Miller et al., "Gene-expression profiles and transcriptional regulatory pathways that underlie the identity and diversity of mouse tissue macrophages," Nature Immunology, vol. 13, no. 11, pp. 1118-1128, 2012.

[6] Y. Lavin, D. Winter, R. Blecher-Gonen et al., "Tissue-resident macrophage enhancer landscapes are shaped by the local microenvironment," Cell, vol. 159, no. 6, pp. 1312-1326, 2014.

[7] Y. Okabe and R. Medzhitov, "Tissue-specific signals control reversible program of localization and functional polarization of macrophages," Cell, vol. 157, no. 4, pp. 832-844, 2014.

[8] S. Heinz, C. Benner, N. Spann et al., "Simple combinations of lineage-determining transcription factors prime cis-regulatory elements required for macrophage and b cell identities," Molecular Cell, vol. 38, no. 4, pp. 576-589, 2010.

[9] L. Escoubet-Lozach, C. Benner, M. U. Kaikkonen et al., "Mechanisms establishing tlr4-responsive activation states of inflammatory response genes," PLoS Genetics, vol. 7, no. 12, Article ID e1002401, 2011.

[10] S. Ghisletti and G. Natoli, "Deciphering cis-regulatory control in inflammatory cells," Philosophical Transactions of the Royal Society of London, Series B: Biological Sciences, vol. 368, no. 1620, Article ID 20120370, 2013.

[11] S. Ghisletti, I. Barozzi, F. Mietton et al., "Identification and characterization of enhancers controlling the inflammatory gene expression program in macrophages," Immunity, vol. 32, no. 3, pp. 317-328, 2010.

[12] J. D. Stender and C. K. Glass, "Epigenomic control of the innate immune response," Current Opinion in Pharmacology, vol. 13, no. 4, pp. 582-587, 2013.

[13] A. Di Lorenzo and M. T. Bedford, "Histone arginine methylation," FEBS Letters, vol. 585, no. 13, pp. 2024-2031, 2011.

[14] X. Zhang, H. Wen, and X. Shi, "Lysine methylation: beyond histones," Acta Biochimica et Biophysica Sinica, vol. 44, no. 1, pp. 14-27, 2012.

[15] M. G. Guenther, S. S. Levine, L. A. Boyer, R. Jaenisch, and R. A. Young, "A chromatin landmark and transcription initiation at most promoters in human cells," Cell, vol. 130, no. 1, pp. 77-88, 2007.

[16] M. P. Creyghton, A. W. Cheng, G. G. Welstead et al., "Histone H3K27ac separates active from poised enhancers and predicts developmental state," Proceedings of the National Academy of Sciences of the United States of America, vol. 107, no. 50, pp. 21931-21936, 2010.

[17] R. Ostuni and G. Natoli, "Transcriptional control of macrophage diversity and specialization," European Journal of Immunology, vol. 41, no. 9, pp. 2486-2490, 2011.

[18] N. D. Heintzman, G. C. Hon, R. D. Hawkins et al., "Histone modifications at human enhancers reflect global cell-typespecific gene expression," Nature, vol. 459, no. 7243, pp. 108-112, 2009.

[19] M. Garber, N. Yosef, A. Goren et al., "A high-throughput chromatin immunoprecipitation approach reveals principles of dynamic gene regulation in mammals," Molecular Cell, vol. 47, no. 5, pp. 810-822, 2012.

[20] F. L. Jin, Y. Li, B. Ren, and R. Natarajan, "PU.1 and C/EBP $\alpha$ synergistically program distinct response to NF- $\kappa \mathrm{B}$ activation through establishing monocyte specific enhancers," Proceedings of the National Academy of Sciences of the United States of America, vol. 108, no. 13, pp. 5290-5295, 2011.

[21] R. Medzhitov and T. Horng, "Transcriptional control of the inflammatory response," Nature Reviews Immunology, vol. 9, no. 10, pp. 692-703, 2009.
[22] M. U. Kaikkonen, N. J. Spann, S. Heinz et al., "Remodeling of the enhancer landscape during macrophage activation is coupled to enhancer transcription," Molecular Cell, vol. 51, no. 3, pp. 310325, 2013.

[23] G. Natoli, "Specialized chromatin patterns in the control of inflammatory gene expression," Current Topics in Microbiology and Immunology, vol. 349, pp. 61-72, 2011.

[24] S. T. Smale, "Selective transcription in response to an inflammatory stimulus," Cell, vol. 140, no. 6, pp. 833-844, 2010.

[25] D. C. Hargreaves, T. Horng, and R. Medzhitov, "Control of inducible gene expression by signal-dependent transcriptional elongation," Cell, vol. 138, no. 1, pp. 129-145, 2009.

[26] K. Adelman, M. A. Kennedy, S. Nechaev et al., "Immediate mediators of the inflammatory response are poised for gene activation through RNA polymerase II stalling," Proceedings of the National Academy of Sciences of the United States of America, vol. 106, no. 43, pp. 18207-18212, 2009.

[27] V. R. Ramirez-Carrozzi, D. Braas, D. M. Bhatt et al., "A unifying model for the selective regulation of inducible transcription by CpG islands and nucleosome remodeling," Cell, vol. 138, no. 1, pp. 114-128, 2009.

[28] R. Ostuni, V. Piccolo, I. Barozzi et al., "Latent enhancers activated by stimulation in differentiated cells," Cell, vol. 152, no. 1-2, pp. 157-171, 2013.

[29] G. D. Barish, R. T. Yu, M. Karunasiri et al., "Bcl-6 and NF- $\kappa$ B cistromes mediate opposing regulation of the innate immune response," Genes and Development, vol. 24, no. 24, pp. 2760 $2765,2010$.

[30] J. van den Bossche, A. E. Neele, M. A. Hoeksema et al., "Inhibiting epigenetic enzymes to improve atherogenic macrophage functions," Biochemical and Biophysical Research Communications, vol. 455, no. 3-4, pp. 396-402, 2014.

[31] H. L. Eames, D. G. Saliba, T. Krausgruber, A. Lanfrancotti, G. Ryzhakov, and I. A. Udalova, "KAP1/TRIM28: an inhibitor of IRF5 function in inflammatory macrophages," Immunobiology, vol. 217, no. 12, pp. 1315-1324, 2012.

[32] T. C. Fang, U. Schaefer, I. Mecklenbrauker et al., "Histone $\mathrm{H} 3$ lysine 9 di-methylation as an epigenetic signature of the interferon response," Journal of Experimental Medicine, vol. 209, no. 4, pp. 661-669, 2012.

[33] Y. Sang, W. Brichalli, R. R. R. Rowland, and F. Blecha, "Genome-wide analysis of antiviral signature genes in porcine macrophages at different activation statuses," PLoS ONE, vol. 9, no. 2, Article ID e87613, 2014.

[34] N. A. Kittan, R. M. Allen, A. Dhaliwal et al., "Cytokine induced phenotypic and epigenetic signatures are key to establishing specific macrophage phenotypes," PLoS ONE, vol. 8, no. 10, Article ID e78045, 2013.

[35] L. Austenaa, I. Barozzi, A. Chronowska et al., "The histone methyltransferase Wbp7 controls macrophage function through GPI glycolipid anchor synthesis," Immunity, vol. 36, no. 4, pp. 572-585, 2012.

[36] M. Xia, J. Liu, X. Wu et al., "Histone methyltransferase ashll suppresses interleukin-6 production and inflammatory autoimmune diseases by inducing the ubiquitin-editing enzyme A20," Immunity, vol. 39, no. 3, pp. 470-481, 2013.

[37] G. L. Xu, G. L. Liu, S. D. Xiong, H. Y. Liu, X. Chen, and B. Zheng, "The histone methyltransferase Smyd2 is a negative regulator of macrophage activation by suppressing interleukin 6 (IL-6) and tumor necrosis factor $\alpha$ (TNF- $\alpha$ )," Journal of Biological Chemistry, vol. 290, no. 9, pp. 5414-5423, 2015. 
[38] J. D. Stender, G. Pascual, W. Liu et al., "Control of proinflammatory gene programs by regulated trimethylation and demethylation of histone H4K20," Molecular Cell, vol. 48, no. 1, pp. 28-38, 2012.

[39] M. Babu, T. D. Devi, P. Makinen et al., "Differential promoter methylation of macrophage genes is associated with impaired vascular growth in ischemic muscles of hyperlipidemic and type 2 diabetic mice genome-wide promoter methylation study," Circulation Research, vol. 117, no. 3, pp. 289-299, 2015.

[40] C. Cheng, C. Huang, T.-T. Ma et al., "SOCS1 hypermethylation mediated by DNMT1 is associated with lipopolysaccharideinduced inflammatory cytokines in macrophages," Toxicology Letters, vol. 225, no. 3, pp. 488-497, 2014.

[41] H. P. Du, J. Li, S. J. You et al., "DNA methylation in cystathionine- $\gamma$-lyase (CSE) gene promoter induced by ox-LDL in macrophages and in apoE knockout mice," Biochemical and Biophysical Research Communications, vol. 469, no. 3, pp. 776782, 2016.

[42] X. Yang, X. Wang, D. Liu, L. Yu, B. Xue, and H. Shi, "Epigenetic regulation of macrophage polarization by DNA methyltransferase 3b," Molecular Endocrinology, vol. 28, no. 4, pp. 565-574, 2014.

[43] D. van Essen, Y. Zhu, and S. Saccani, "A feed-forward circuit controlling inducible NF- $\kappa \mathrm{B}$ target gene activation by promoter histone demethylation," Molecular Cell, vol. 39, no. 5, pp. 750760, 2010 .

[44] Y. Zhu, D. van Essen, and S. Saccani, "Cell-type-specific control of enhancer activity by H3K9 trimethylation," Molecular Cell, vol. 46, no. 4, pp. 408-423, 2012.

[45] L. Kruidenier, C.-W. Chung, Z. Cheng et al., "A selective jumonji H3K27 demethylase inhibitor modulates the proinflammatory macrophage response," Nature, vol. 488, no. 7411, pp. 404-408, 2012.

[46] N. D. Das, K. H. Jung, M. R. Choi, H. S. Yoon, S. H. Kim, and Y. G. Chai, "Gene networking and inflammatory pathway analysis in a JMJD3 knockdown human monocytic cell line," Cell Biochemistry and Function, vol. 30, no. 3, pp. 224-232, 2012.

[47] K. A. Gallagher, A. Joshi, W. F. Carson et al., "Epigenetic changes in bone marrow progenitor cells influence the inflammatory phenotype and alter wound healing in type 2 diabetes," Diabetes, vol. 64, no. 4, pp. 1420-1430, 2015.

[48] Q. Yan, L. Sun, Z. Zhu, L. Wang, S. Li, and R. D. Ye, "Jmjd3mediated epigenetic regulation of inflammatory cytokine gene expression in serum amyloid A-stimulated macrophages," Cellular Signalling, vol. 26, no. 9, pp. 1783-1791, 2014.

[49] Y. Tang, T. Li, J. Li et al., "Jmjd3 is essential for the epigenetic modulation of microglia phenotypes in the immune pathogenesis of Parkinson's disease," Cell Death and Differentiation, vol. 21, no. 3, pp. 369-380, 2014.

[50] M. Ishii, H. Wen, C. A. S. Corsa et al., "Epigenetic regulation of the alternatively activated macrophage phenotype," Blood, vol. 114, no. 15, pp. 3244-3254, 2009.

[51] T. Satoh, O. Takeuchi, A. Vandenbon et al., "The Jmjd3-Irf4 axis regulates M2 macrophage polarization and host responses against helminth infection," Nature Immunology, vol. 11, no. 10, pp. 936-944, 2010.

[52] Q. Zhang, K. Zhao, Q. Shen et al., "Tet2 is required to resolve inflammation by recruiting Hdac2 to specifically repress IL-6," Nature, vol. 525, no. 7569, pp. 389-393, 2015.

[53] A. Chauhan, F. Z. Quenum, A. Abbas et al., "Epigenetic modulation of microglial inflammatory gene loci in helminth-induced immune suppression: implications for immune regulation in neurocysticercosis," ASN Neuro, vol. 7, no. 4, pp. 1-12, 2015.

[54] D. Feng, N. Sangster-Guity, R. Stone et al., "Differential requirement of histone acetylase and deacetylase activities for IRF5mediated proinflammatory cytokine expression," The Journal of Immunology, vol. 185, no. 10, pp. 6003-6012, 2010.

[55] T. Roger, J. Lugrin, D. Le Roy et al., "Histone deacetylase inhibitors impair innate immune responses to Toll-like receptor agonists and to infection," Blood, vol. 117, no. 4, pp. 1205-1217, 2011.

[56] M. Mombelli, J. Lugrin, I. Rubino et al., "Histone deacetylase inhibitors impair antibacterial defenses of macrophages," Journal of Infectious Diseases, vol. 204, no. 9, pp. 1367-1374, 2011.

[57] V. Kannan, N. Brouwer, U.-K. Hanisch, T. Regen, B. J. L. Eggen, and H. W. G. M. Boddeke, "Histone deacetylase inhibitors suppress immune activation in primary mouse microglia," Journal of Neuroscience Research, vol. 91, no. 9, pp. 1133-1142, 2013.

[58] J. Lugrin, X. C. Ding, D. Le Roy et al., "Histone deacetylase inhibitors repress macrophage migration inhibitory factor (MIF) expression by targeting MIF gene transcription through a local chromatin deacetylation," Biochimica et Biophysica Acta (BBA)_Molecular Cell Research, vol. 1793, no. 11, pp. 1749-1758, 2009.

[59] G. Wang, Y. Shi, X. Jiang et al., "HDAC inhibition prevents white matter injury by modulating microglia/macrophage polarization through the GSK3 $\beta /$ PTEN/Akt axis," Proceedings of the National Academy of Sciences of the United States of America, vol. 112, no. 9, pp. 2853-2858, 2015.

[60] M. Cabanel, C. Brand, M. C. Oliveira-Nunes et al., "Epigenetic control of macrophage shape transition towards an atypical elongated phenotype by histone deacetylase activity," PLoS ONE, vol. 10, no. 7, Article ID e0132984, 2015.

[61] R. N. Laribee and M. J. Klemsz, "Loss of PU.1 expression following inhibition of histone deacetylases," The Journal of Immunology, vol. 167, no. 9, pp. 5160-5166, 2001.

[62] N. Serrat, S. Pereira-Lopes, M. Comalada, J. Lloberas, and A. Celada, "Deacetylation of $\mathrm{C} / \mathrm{EBP} \beta$ is required for IL-4-induced arginase-1 expression in murine macrophages," European Journal of Immunology, vol. 42, no. 11, pp. 3028-3037, 2012.

[63] C. Wu, A. Li, Y. Leng, Y. Li, and J. Kang, "Histone deacetylase inhibition by sodium valproate regulates polarization of macrophage subsets," DNA and Cell Biology, vol. 31, no. 4, pp. 592-599, 2012.

[64] M. A. Halili, M. R. Andrews, L. I. Labzin et al., "Differential effects of selective HDAC inhibitors on macrophage inflammatory responses to the Toll-like receptor 4 agonist LPS," Journal of Leukocyte Biology, vol. 87, no. 6, pp. 1103-1114, 2010.

[65] X. Kong, M. Fang, P. Li, F. Fang, and Y. Xu, "HDAC2 deacetylates class II transactivator and suppresses its activity in macrophages and smooth muscle cells," Journal of Molecular and Cellular Cardiology, vol. 46, no. 3, pp. 292-299, 2009.

[66] X. Chen, I. Barozzi, A. Termanini et al., "Requirement for the histone deacetylase Hdac3 for the inflammatory gene expression program in macrophages," Proceedings of the National Academy of Sciences of the United States of America, vol. 109, no. 42, pp. E2865-E2874, 2012.

[67] M. A. Hoeksema, M. J. Gijbels, J. Van den Bossche et al., “Targeting macrophage Histone deacetylase 3 stabilizes atherosclerotic lesions," EMBO Molecular Medicine, vol. 6, no. 9, pp. 1124-1132, 2014. 
[68] M. R. Shakespear, D. M. Hohenhaus, G. M. Kelly et al., "Histone deacetylase 7 promotes toll-like receptor 4-dependent proinflammatory gene expression in macrophages," The Journal of Biological Chemistry, vol. 288, no. 35, pp. 25362-25374, 2013.

[69] Q. Cao, S. X. Rong, J. J. Repa, R. S. Clair, J. S. Parks, and N. Mishra, "Histone deacetylase 9 represses cholesterol efflux and alternatively activated macrophages in atherosclerosis development," Arteriosclerosis, Thrombosis, and Vascular Biology, vol. 34, no. 9, pp. 1871-1879, 2014.

[70] S.-O. Ka, M.-Y. Song, E. J. Bae, and B.-H. Park, "Myeloid SIRT1 regulates macrophage infiltration and insulin sensitivity in mice fed a high-fat diet," Journal of Endocrinology, vol. 224, no. 2, pp. 109-118, 2015.

[71] Z. Shen, J. M. Ajmo, C. Q. Rogers et al., "Role of SIRT1 in regulation of LPS- or two ethanol metabolites-induced TNF$\alpha$ production in cultured macrophage cell lines," American Journal of Physiology-Gastrointestinal and Liver Physiology, vol. 296, no. 5, pp. G1047-G1053, 2009.

[72] T. T. Schug, Q. Xu, H. Gao et al., "Myeloid deletion of SIRT1 induces inflammatory signaling in response to environmental stress," Molecular and Cellular Biology, vol. 30, no. 19, pp. 47124721, 2010.

[73] T. Yoshizaki, S. Schenk, T. Imamura et al., "SIRT1 inhibits inflammatory pathways in macrophages and modulates insulin sensitivity," American Journal of Physiology -Endocrinology and Metabolism, vol. 298, no. 3, pp. E419-E428, 2010.

[74] R. Zhang, H.-Z. Chen, J.-J. Liu et al., "SIRT1 suppresses activator protein-1 transcriptional activity and cyclooxygenase- 2 expression in macrophages," The Journal of Biological Chemistry, vol. 285, no. 10, pp. 7097-7110, 2010.

[75] G. Lo Sasso, K. J. Menzies, A. Mottis et al., "SIRT2 deficiency modulates macrophage polarization and susceptibility to experimental colitis," PLoS ONE, vol. 9, no. 7, Article ID e103573, 2014.

[76] M. J. Kim, D. W. Kim, J. H. Park et al., "PEP-1-SIRT2 inhibits inflammatory response and oxidative stress-induced cell death via expression of antioxidant enzymes in murine macrophages," Free Radical Biology and Medicine, vol. 63, pp. 432-445, 2013.

[77] T. F. Pais, É. M. Szego, O. Marques et al., "The NAD-dependent deacetylase sirtuin 2 is a suppressor of microglial activation and brain inflammation," The EMBO Journal, vol. 32, no. 19, pp. 2603-2616, 2013.

[78] A. Villagra, F. Cheng, H.-W. Wang et al., “The histone deacetylase HDAC11 regulates the expression of interleukin 10 and immune tolerance," Nature Immunology, vol. 10, no. 1, pp. 92100, 2009.

[79] H. W. Wang, F. D. Cheng, K. Woan et al., "Histone deacetylase inhibitor LAQ824 augments inflammatory responses in macrophages through transcriptional regulation of IL-10," The Journal of Immunology, vol. 186, no. 7, pp. 3986-3996, 2011.

[80] D. Stammler, T. Eigenbrod, S. Menz et al., "Inhibition of histone deacetylases permits lipopolysaccharide-mediated secretion of bioactive IL-1 via a caspase-1-independent mechanism," The Journal of Immunology, vol. 195, no. 11, pp. 5421-5431, 2015.

[81] F. O. Martinez and S. Gordon, "The M1 and M2 paradigm of macrophage activation: time for reassessment," F1000Prime Reports, vol. 6, article 13, 2014.

[82] D. Zhou, C. Huang, Z. Lin et al., "Macrophage polarization and function with emphasis on the evolving roles of coordinated regulation of cellular signaling pathways," Cellular Signalling, vol. 26, no. 2, pp. 192-197, 2014.
[83] D. Tugal, X. Liao, and M. K. Jain, "Transcriptional control of macrophage polarization," Arteriosclerosis, Thrombosis, and Vascular Biology, vol. 33, no. 6, pp. 1135-1144, 2013.

[84] G. Liu and E. Abraham, "MicroRNAs in immune response and macrophage polarization," Arteriosclerosis, Thrombosis, and Vascular Biology, vol. 33, no. 2, pp. 170-177, 2013.

[85] J. W. Graff, A. M. Dickson, G. Clay, A. P. McCaffrey, and M. E. Wilson, "Identifying functional microRNAs in macrophages with polarized phenotypes," The Journal of Biological Chemistry, vol. 287, no. 26, pp. 21816-21825, 2012.

[86] G. Zhuang, C. Meng, X. Guo et al., "A novel regulator of macrophage activation: miR-223 in obesity-associated adipose tissue inflammation," Circulation, vol. 125, no. 23, pp. 28922903, 2012.

[87] M. He, Z. Xu, T. Ding, D.-M. Kuang, and L. Zheng, "MicroRNA155 regulates inflammatory cytokine production in tumorassociated macrophages via targeting C/EBP $\beta$," Cellular \& Molecular Immunology, vol. 6, no. 5, pp. 343-352, 2009.

[88] E. D. Ponomarev, T. Veremeyko, N. Barteneva, A. M. Krichevsky, and H. L. Weiner, "MicroRNA-124 promotes microglia quiescence and suppresses EAE by deactivating macrophages via the C/EBP- $\alpha$-PU.1 pathway," Nature Medicine, vol. 17, no. 1, pp. 64-70, 2011.

[89] R. T. Martinez-Nunez, F. Louafi, and T. Sanchez-Elsner, “The interleukin 13 (IL-13) pathway in human macrophages is modulated by microRNA-155 via direct targeting of interleukin 13 receptor $\alpha 1$ (IL13R $\alpha 1$ )," The Journal of Biological Chemistry, vol. 286, no. 3, pp. 1786-1794, 2011.

[90] M. Etzrodt, V. Cortez-Retamozo, A. Newton et al., "Regulation of monocyte functional heterogeneity by miR-146a and Relb," Cell Reports, vol. 1, no. 4, pp. 317-324, 2012.

[91] S. Banerjee, N. Xie, H. Cui et al., "MicroRNA let-7c regulates macrophage polarization," The Journal of Immunology, vol. 190, no. 12, pp. 6542-6549, 2013.

[92] S. R. Quinn and L. A. O'Neill, "A trio of microRNAs that control Toll-like receptor signalling," International Immunology, vol. 23, no. 7, pp. 421-425, 2011.

[93] S. K. Biswas and A. Mantovani, "Macrophage plasticity and interaction with lymphocyte subsets: cancer as a paradigm," Nature Immunology, vol. 11, no. 10, pp. 889-896, 2010.

[94] J. Xue, S. V. Schmidt, J. Sander et al., “Transcriptome-based network analysis reveals a spectrum model of human macrophage activation," Immunity, vol. 40, no. 2, pp. 274-288, 2014.

[95] A. Sica and A. Mantovani, "Macrophage plasticity and polarization: in vivo veritas," The Journal of Clinical Investigation, vol. 122, no. 3, pp. 787-795, 2012.

[96] A. Mantovani, S. Sozzani, M. Locati, P. Allavena, and A. Sica, "Macrophage polarization: tumor-associated macrophages as a paradigm for polarized M2 mononuclear phagocytes," Trends in Immunology, vol. 23, no. 11, pp. 549-555, 2002.

[97] B. N. Melgert, N. H. Ten Hacken, B. Rutgers, W. Timens, D. S. Postma, and M. N. Hylkema, "More alternative activation of macrophages in lungs of asthmatic patients," Journal of Allergy and Clinical Immunology, vol. 127, no. 3, pp. 831-833, 2011.

[98] W. Noël, G. Raes, G. H. Ghassabeh, P. De Baetselier, and A. Beschin, "Alternatively activated macrophages during parasite infections," Trends in Parasitology, vol. 20, no. 3, pp. 126-133, 2004.

[99] C. N. Lumeng, J. L. Bodzin, and A. R. Saltiel, "Obesity induces a phenotypic switch in adipose tissue macrophage polarization," Journal of Clinical Investigation, vol. 117, no. 1, pp. 175-184, 2007. 
[100] S. P. Weisberg, D. McCann, M. Desai, M. Rosenbaum, R. L. Leibel, and A. W. Ferrante Jr., "Obesity is associated with macrophage accumulation in adipose tissue," The Journal of Clinical Investigation, vol. 112, no. 12, pp. 1796-1808, 2003.

[101] S. Mukhopadhyay, A. S. Ramadass, A. Akoulitchev, and S. Gordon, "Formation of distinct chromatin conformation signatures epigenetically regulate macrophage activation," International Immunopharmacology, vol. 18, no. 1, pp. 7-11, 2014.

[102] M. G. Goll and T. H. Bestor, "Eukaryotic cytosine methyltransferases," Annual Review of Biochemistry, vol. 74, pp. 481-514, 2005.

[103] A. K. Maunakea, R. P. Nagarajan, M. Bilenky et al., "Conserved role of intragenic DNA methylation in regulating alternative promoters," Nature, vol. 466, no. 7303, pp. 253-257, 2010.

[104] M. Zilbauer, T. F. Rayner, C. Clark et al., "Genome-wide methylation analyses of primary human leukocyte subsets identifies functionally important cell-type-specific hypomethylated regions," Blood, vol. 122, no. 25, pp. e52-e60, 2013.

[105] Q. Cao, X. Wang, L. Jia et al., "Inhibiting DNA methylation by 5 -Aza- 2 '-deoxycytidine ameliorates atherosclerosis through suppressing macrophage inflammation," Endocrinology, vol. 155, no. 12, pp. 4925-4938, 2014.

[106] A. Das, N. D. Das, K. H. Jung et al., "Proteomic changes induced by histone demethylase JMJD3 in TNF alpha-treated human monocytic (THP-1) cells," Molecular Immunology, vol. 56, no. 1-2, pp. 113-122, 2013.

[107] H. T. Lee, S. K. Kim, S. H. Kim et al., "Transcription-related element gene expression pattern differs between microglia and macrophages during inflammation," Inflammation Research, vol. 63, no. 5, pp. 389-397, 2014.

[108] P. Przanowski, M. Dabrowski, A. Ellert-Miklaszewska et al., "The signal transducers Stat1 and Stat3 and their novel target Jmjd3 drive the expression of inflammatory genes in microglia," Journal of Molecular Medicine, vol. 92, no. 3, pp. 239-254, 2014.

[109] F. De Santa, V. Narang, Z. H. Yap et al., "Jmjd3 contributes to the control of gene expression in LPS-activated macrophages," The EMBO Journal, vol. 28, no. 21, pp. 3341-3352, 2009.

[110] M. Tahiliani, K. P. Koh, Y. Shen et al., "Conversion of 5methylcytosine to 5-hydroxymethylcytosine in mammalian DNA by MLL partner TET1," Science, vol. 324, no. 5929, pp. 930935, 2009.

[111] W. A. Pastor, L. Aravind, and A. Rao, "TETonic shift: biological roles of TET proteins in DNA demethylation and transcription," Nature Reviews Molecular Cell Biology, vol. 14, no. 6, pp. 341356, 2013.

[112] M. M. Dawlaty, A. Breiling, T. Le et al., "Loss of Tet enzymes compromises proper differentiation of embryonic stem cells," Developmental Cell, vol. 29, no. 1, pp. 102-111, 2014.

[113] M. Ko, Y. Huang, A. M. Jankowska et al., "Impaired hydroxylation of 5-methylcytosine in myeloid cancers with mutant TET2," Nature, vol. 468, no. 7325, pp. 839-843, 2010.

[114] S. Ito, L. Shen, Q. Dai et al., "Tet proteins can convert 5methylcytosine to 5-formylcytosine and 5-carboxylcytosine," Science, vol. 333, no. 6047, pp. 1300-1303, 2011.

[115] Y.-F. He, B.-Z. Li, Z. Li et al., "Tet-mediated formation of 5carboxylcytosine and its excision by TDG in mammalian DNA," Science, vol. 333, no. 6047, pp. 1303-1307, 2011.

[116] Y. Li, S. J. Ohms, F. M. Shannon, C. Sun, and J. Y. Fan, "IL2 and GM-CSF are regulated by DNA demethylation during activation of T cells, B cells and macrophages," Biochemical and Biophysical Research Communications, vol. 419, no. 4, pp. 748753, 2012.
[117] K. K. Lee and J. L. Workman, "Histone acetyltransferase complexes: one size doesn't fit all," Nature Reviews Molecular Cell Biology, vol. 8, no. 4, pp. 284-295, 2007.

[118] G. P. Delcuve, D. H. Khan, and J. R. Davie, "Roles of histone deacetylases in epigenetic regulation: emerging paradigms from studies with inhibitors," Clinical Epigenetics, vol. 4, article 5, 2012.

[119] S.-B. Han and J. K. Lee, "Anti-inflammatory effect of trichostatin-A on murine bone marrow-derived macrophages," Archives of Pharmacal Research, vol. 32, no. 4, pp. 613-624, 2009.

[120] N. Serrat, C. Sebastian, S. Pereira-Lopes, L. Valverde-Estrella, J. Lloberas, and A. Celada, "The response of secondary genes to lipopolysaccharides in macrophages depends on histone deacetylase and phosphorylation of $\mathrm{C} / \mathrm{EBP} \beta$," The Journal of Immunology, vol. 192, no. 1, pp. 418-426, 2014.

[121] Y. Jeong, R. Du, X. Zhu et al., "Histone deacetylase isoforms regulate innate immune responses by deacetylating mitogenactivated protein kinase phosphatase-1," Journal of Leukocyte Biology, vol. 95, no. 4, pp. 651-659, 2014.

[122] S. E. Mullican, C. A. Gaddis, T. Alenghat et al., "Histone deacetylase 3 is an epigenomic brake in macrophage alternative activation," Genes \& Development, vol. 25, no. 23, pp. 24802488,2011

[123] S. Stein, C. Lohmann, N. Schäfer et al., "SIRT1 decreases Lox-1mediated foam cell formation in atherogenesis," European Heart Journal, vol. 31, no. 18, pp. 2301-2309, 2010. 


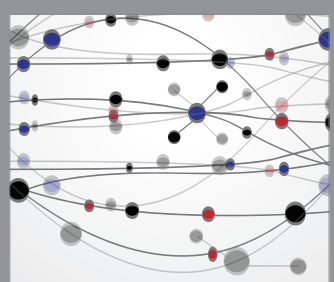

The Scientific World Journal
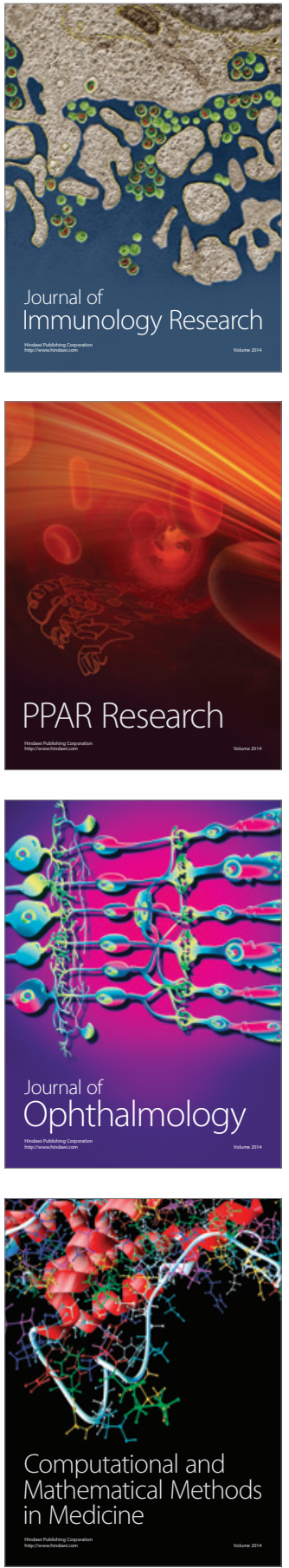

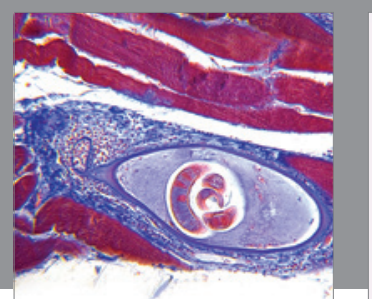

Gastroenterology Research and Practice

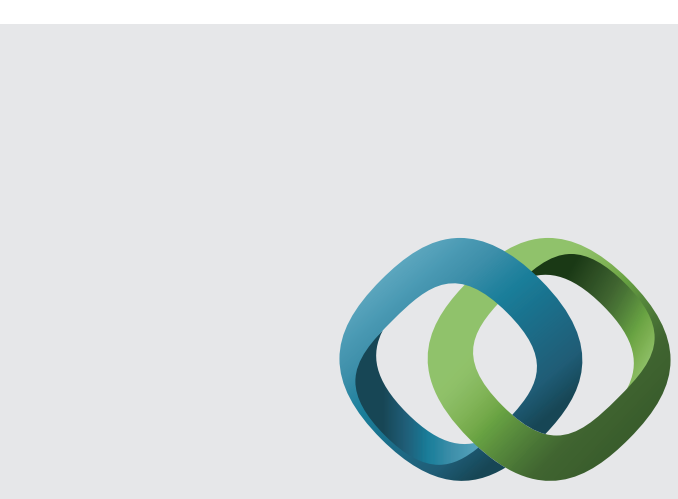

\section{Hindawi}

Submit your manuscripts at

http://www.hindawi.com
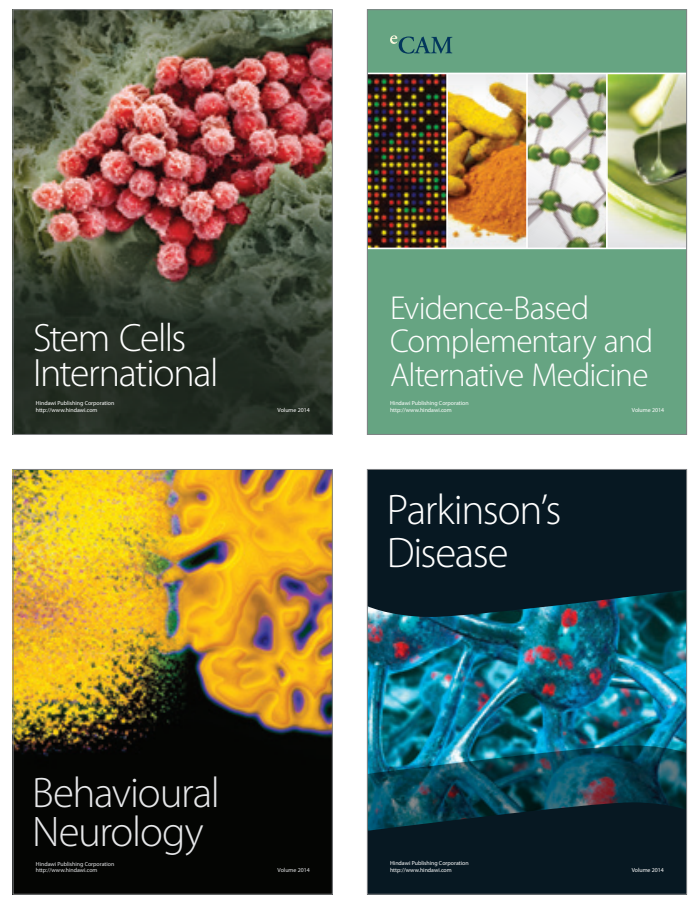
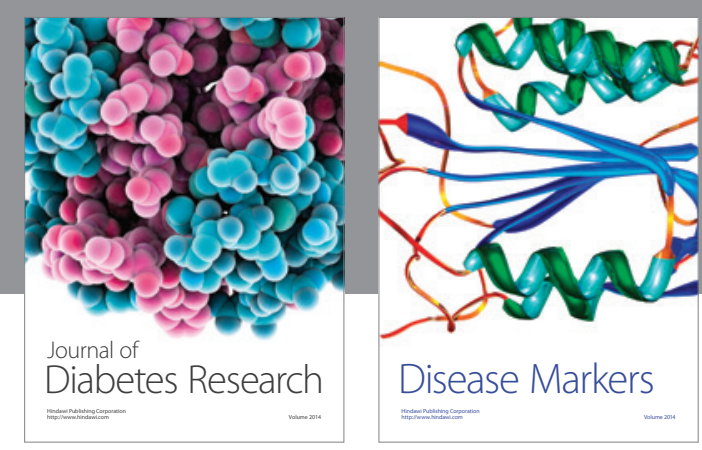

Disease Markers
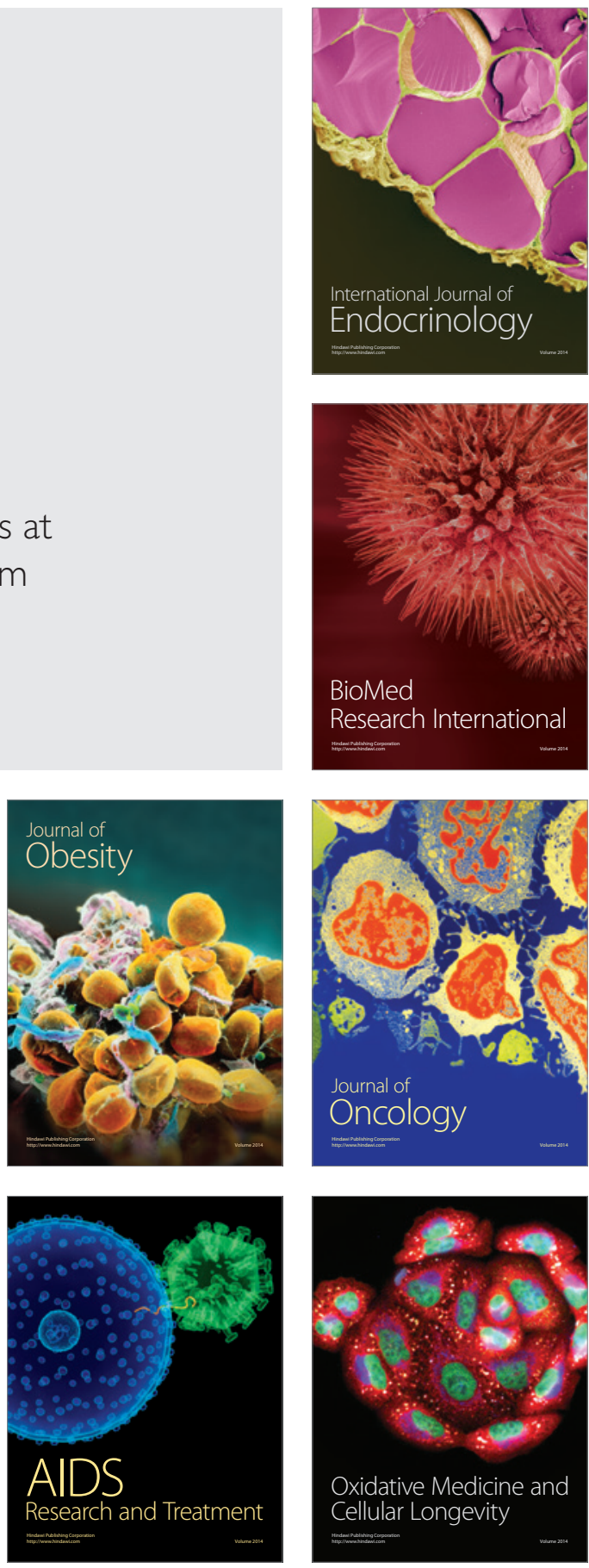